\title{
Systems Biology and the Integration of Mechanistic Explanation and Mathematical Explanation
}

\author{
Ingo Brigandt \\ Department of Philosophy, University of Alberta \\ 2-40 Assiniboia Hall, Edmonton, AB T6G2E7, Canada \\ Email address: brigandt@ualberta.ca
}

\begin{abstract}
The paper discusses how systems biology is working toward complex accounts that integrate explanation in terms of mechanisms and explanation by mathematical models - which some philosophers have viewed as rival models of explanation. Systems biology is an integrative approach, and it strongly relies on mathematical modeling. Philosophical accounts of mechanisms capture integrative in the sense of multilevel and multifield explanations, yet accounts of mechanistic explanation (as the analysis of a whole in terms of its structural parts and their qualitative interactions) have failed to address how a mathematical model could contribute to such explanations. I discuss how mathematical equations can be explanatorily relevant. Several cases from systems biology are discussed to illustrate the interplay between mechanistic research and mathematical modeling, and I point to questions about qualitative phenomena (rather than the explanation of quantitative details), where quantitative models are still indispensable to the explanation. Systems biology shows that a broader philosophical conception of mechanisms is needed, which takes into account functional-dynamical aspects, interaction in complex networks with feedback loops, system-wide functional properties such as distributed functionality and robustness, and a mechanism's ability to respond to perturbations (beyond its actual operation). I offer general conclusions for philosophical accounts of explanation.
\end{abstract}

Keywords: Systems biology, integration, mechanistic explanation, mathematical models, mechanisms 


\section{Introduction}

Current philosophical accounts of integration and integrative explanations can be seen as a philosophical alternative to reduction and reductive explanation (Brigandt, 2013a; Brigandt \& Love, 2010, 2012b; Plutynski, this issue). By assuming that the knowledge from several fields can be logically deduced from a more fundamental (lower-level) theory, the model of theory reduction proved unable to capture the complex relations among biological ideas. Initial accounts of integration conceptualized the non-reductive yet systematic relations among fields as being provided by particular theories (so called interfield theories; Darden \& Maull, 1977; Maull, 1977), but nowadays broader accounts are available, which do not require theories to be central epistemic units for all of biology (Brigandt, 2010; Leonelli, this issue; O'Malley, this issue). One approach is to use the notion of a mechanism, which is currently popular in philosophy of science (Machamer et al., 2000; Glennan et al., 2002; Craver \& Darden, 2005).

For various branches of experimental biology, including molecular biology, cell biology, and neuroscience, accounts of mechanistic explanation have proven fruitful, among other things because they are able to articulate the nature of multifield, multilevel explanations - as opposed to purely reductive explanations - given that different disciplines can contribute to the elucidation of a mechanism and mechanisms involve the interaction of entities on several levels of organization (Bechtel, 2006; Craver, 2007; Darden, 2005). Moreover, mechanisms are discovered in a piecemeal fashion, and mechanistic research may alternate between downward, reductive episodes and upward, integrative episodes (Bechtel, 2010, this issue; Craver, 2005). As a result, such philosophical accounts pay attention to discovery and the change of knowledge and research strategies and thereby address not only the product of science (e.g., a finished explanation) but also the practice and dynamic process of science (Brigandt, 2013a, 2013b; Gerson, this issue; Griesemer, this issue).

Systems biology is nowadays thriving, and it is clearly an integrative and interdisciplinary approach. It attempts to explain complex biological systems using a variety of conceptual and experimental resources. The focus is on system-wide behavior rather than the properties of a few isolated components or causal pathways of a system. Due to the availability of information about a plethora of molecular and cellular entities provided by functional genomics, proteomics, and metabolomics projects, systems biology nowadays has a clear molecular-mechanistic face. At the 
same time, the characteristic feature of systems biology is its reliance on mathematical models (Wolkenhauer \& Muir, 2011). This may be at odds with philosophers' conceptualization of mechanistic explanation as the explanation of a whole in terms of its physical parts, including the spatial organization of and qualitative interactions among parts. Philosophical accounts of mechanistic explanation have usually been silent about how a mathematical model could contribute to an explanation at all; in fact, causal-mechanistic accounts have been developed as an alternative to traditional models of explanation as derivation from quantitatively formulated laws (Brigandt, 2013a; Craver, 2007). Yet systems biology does appear to explain using equations and quantitative models (Baetu, in press; Fagan, 2012).

In this paper, I argue that among its many other integrative aspects, systems biology is working toward an integration of mechanistic explanation and mathematical explanation, i.e., a kind of explanation that includes both reference to spatial parts and mathematical equations. This calls for a broader philosophical conception of what a mechanistic explanation is. My thesis is in line with Bill Bechtel's and Adele Abrahamsen's notion of 'dynamic mechanistic explanation' (Bechtel, 2011, 2012, this issue; Bechtel \& Abrahamsen, 2010, 2011), but will go beyond previous accounts in two ways. First, given that mechanists such as Carl Craver (2007) have highlighted the difference between merely modeling and explaining a phenomenon, rather than just indicating that mathematical modeling plays some epistemic role, I specifically argue that mathematical models are indispensable ingredients of some explanations in molecular biology. In fact, while it is trivial that a mathematical representation is needed when accounting for the quantitative aspects or precise temporal dynamics of a system, I will point to several qualitative phenomena to be explained where a quantitative explanation is still required. Second, beyond the example of circadian rhythms discussed by Bechtel and Abrahamsen, I address systems biology as a larger domain and survey several cases that illustrate why equations can be explanatorily indispensable.

The following section gives a brief overview of systems biology. Section 3 provides a general account of how mathematical equations can have explanatorily relevance, but also of when a mathematical model can omit mechanistic detail and still be explanatory. Section 4 surveys several cases from systems biology that illustrate both that its mathematical models are developed and tested based on molecular-mechanistic information, and that there are qualitative explananda necessitating a quantitative explanation. In addition to drawing implications for 
philosophical accounts of mechanistic explanation and explanation in general, the concluding section will also use the case studies to call for a broader ontological conception of mechanisms.

\section{Systems biology}

Systems biology is not so much a (single) field, but may better be described as an (interdisciplinary) approach. For systems biology studies a variety of phenomena from different domains, including biochemical systems (e.g., enzyme activity regulation and flux in metabolic pathways), cellular processes (e.g., gene regulation, protein transport, signaling pathways, the cell cycle, and apoptosis), cell-cell interaction such as cell-cell signaling, as well as cell differentiation and organismal development (Boogerd et al., 2007b; Kitano, 2001; Klipp et al., 2010; Noble, 2006). Even an individual scientist may deal with cases from various biological domains in her overall research. While most of the phenomena studied by systems biologists are processes taking place within single organisms or even single cells (Helms, 2008), there is also research pertaining to the interaction of microorganisms or the distribution and transfer of genes across whole microbial communities (e.g., using data of metagenomics projects), so that systems biology can have connections to ecology (Crawford et al., 2005; Jansson et al., 2012). Studies on (changes in) gene regulatory networks are germane to evolutionary biology (Davidson, 2006; Davidson \& Erwin, 2006; Linksvayer et al., 2012; O'Malley \& Soyer, 2012). Of course, research on the workings of biological systems also has medical applications in view, most notably in the context of cancer biology (Faratian et al., 2009; Kitano, 2004b; Patel \& Nagl, 2010; Wang, 2010), and such broader technological applications as synthetic biology (Fu \& Panke, 2009). Generally, what makes a study an instance of 'systems biology' is that aims at understanding a relatively complex biological system, at least a complex pathway or often a complex network of biological entities. Rather than merely studying the structural organization of a system (e.g., the spatial relations of entities), systems biology is about the functional dynamics of biological systems, i.e., accounting for the temporal change of various entities or studying the systemic results of biological processes.

Methodologically, mathematical modeling is a major aspect of theorizing and practice in systems biology, given that mathematical equations and computer simulations are best able to represent the dynamic behavior of complex systems and determine the outcome of such behavior 
(and in addition to this capture quantitative aspects). Differential equations can be used to describe how the level of some entities change in response to the activities of other entities across time (and across space, if partial differential equations are used), which could be the concentration of a metabolite resulting from direct biochemical interactions, or the transcription level of a gene regulated by other genes (mediated by RNAs and proteins). Some models are non-deterministic and incorporate stochastic factors, and the mathematical analysis of networks has become an important approach (Alon, 2007). (Many of the mathematical and computational tools can also be found in other disciplines, such as physics and engineering; see Hooker, 2011.) Systems biologists tend to endorse a pluralistic methodological approach by recognizing the need to use a variety of theoretical and experimental tools and ideas (Bruggeman et al., 2002; O'Malley \& Dupré, 2005; Westerhoff \& Kell, 2007). Scientific models are conceived as necessarily partial representations of reality, so that many models are needed and different accounts are developed for different purposes, integrating different items of empirical data and different mathematical models. Many systems biologists take a non-reductionist stance by assuming that biological processes cannot be understood in terms of genes alone (Noble, 2006) or by endorsing the notion of distributed functionality as opposed to localized control by certain entities (Krohs \& Callebaut, 2007; Moreno, 2007; Wolkenhauer \& Muir, 2011).

In systems biology, bottom-up approaches start with information about a limited number of molecular components and attempt to predict or explain the effects resulting from their interactions, e.g., the system behavior or emergent features. Top-down approaches, in contrast, proceed from a system's overall behavior and attempt to analyze it, e.g., by breaking system functionality down into functional components. Krohs and Callebaut (2007) distinguish three 'roots' of systems biology in terms of how much information they deliver about component dynamics, system dynamics, and component structure. First, pathway modeling has a tradition of studying enzyme kinetics, the flux in and regulation of metabolic pathways, and also signaling pathways. Such models are in particular used in bottom-up studies. The second root, biological cybernetics, is a top-down approach as it offers a theoretical framework for analyzing system dynamics and information processing on a relatively abstract level. While these two roots of systems biology have a longer history, nowadays 'omics' projects (including transcriptomics, proteomics, and metabolomics) provide a wealth of structural data about a plethora of molecular components of cells. Beyond the computational representation and the statistical analysis of such 
data, a more theoretical framework such as systems biology is to be developed to make biological sense of this data and offer principles that explain complex organismal processes (Karr et al., 2012). Generally, current technologies provide data on the structure, movement, and activity of many molecular entities, with the resolution of a single cell or even a single molecule, which gives systems biology a clear-cut molecular-mechanistic character.

Systems biology is an integrative approach, where even single studies may use empirical information from different biological domains and levels of organization (Noble, 2002). Given that philosophers tend to construe mechanistic explanation as a replacement to traditional models of explanation as derivation from mathematically formulated laws, of particular relevance for this essay is that systems biology appears to integrate mechanistic and mathematical styles of explanation, by using information about concrete molecular and other structural components and making mathematical modeling a central theoretical tool.

\section{No dichotomy between mechanistic explanations and mathematical models}

Philosophical accounts of mechanistic explanation have been developed as an alternative to the traditional idea of scientific explanation as the derivation from laws, e.g., the deductivenomological model (Brigandt, 2013a). In molecular biology and related areas, there are hardly laws, and instead research consists in the discovery of mechanisms, i.e., the breaking of a whole into its concrete structural parts (Bechtel \& Richardson, 1993). Rather than being able to logically deduce an explanandum from laws and other premises, explanatory understanding results from mentally simulating how a mechanism's components are organized and interact so as to bring about the phenomenon to the explained (Bechtel \& Abrahamsen, 2005). The presence of different philosophical models of explanation does not entail that explanation in terms of quantitative principles and in terms of mechanisms have to be incompatible. However, Rasmus Winther (2006) views what he calls formal biology (which explains using mathematical theories) and compositional biology (which explains a whole in terms of its parts) as distinct styles of theorizing used in different fields. And as a developer of a detailed theory of mechanistic explanation, Carl Craver $(2006,2007)$ has repeatedly emphasized the difference between a model merely representing phenomena (and permitting predictions) and a model actually explaining. For Craver, a mechanistic account explains, while he deems several mathematical 
models from cognitive science and neuroscience to be phenomenological, i.e., the models describe a phenomenon but fall short of explaining it (Craver, 2006, 2007, 2008; Kaplan \& Craver, 2011). ${ }^{1}$

Philosophical proponents of mechanistic explanation do not deny that mathematical models can explain, even in the domain of molecular and experimental biology. However, beyond mathematical models being in some cases an important representational tool (and having other non-explanatory epistemic functions; Bogen, 2005), the new mechanists have not investigated what significance the use of equations and mathematical analysis have for the purpose of explanation, in particular what a mathematical model can contribute to some explanations (but see Baetu, in press; Bechtel, 2012, this issue; Brigandt, in press; Fagan, 2012; Levy, in press; Levy \& Bechtel, 2013). I take up this task, by first offering some general philosophical considerations on when a particular equation is indispensable to a given explanation in a mechanistic context. In the subsequent case studies from systems biology, I lay out the explanatory contribution of some mathematical models, illustrating how accounts in systems biology integrate explanation in terms of mechanisms and explanation by mathematical models. While philosophical accounts have created a picture of mechanistic explanation as the analysis of a whole in terms of its structural parts and their qualitative interactions (e.g., binding, activating), I point to instances where functional dynamics and quantitative relations are essential to the explanation (even for some qualitative explananda). A stereotypical portrayal may suggest that a mechanism consists of a fixed stock of entities, has structural parts in a spatial organization, that the activities among the parts are qualitative, that there is a linear causal sequence from start to termination state, and that the mechanism's properties boil down to its actual organization and operation. Beyond the epistemological issue of explanation, in the concluding section I will use the case studies to discuss what important ontological features about mechanisms are left out by such a stereotypical construal.

\footnotetext{
${ }^{1}$ Craver has also stated that some who view explanation as involving the derivation from laws or quantitative principles have problems with capturing the distinction between a mere representation and an explanation (Craver, 2008, p. 1024; Kaplan \& Craver, 2011, pp.608-609). In a previous paper (Brigandt, in press), I construed Craver as taking in general a quite skeptical stance towards the explanatory credentials of mathematical models; however, some of my remarks were a misinterpretation of Craver's discussions.
} 


\subsection{How equations can be explanatorily indispensable in mechanistic accounts}

How can a mathematical model of a molecular system be explanatory in the first place? In a nutshell, an equation (containing several variables) explains when it represents a causal relation among biological entities or their properties (Kaplan \& Craver, 2011), but to explicate this basic idea we have to make use of James Woodward's (2003) theory of causation. For his account is formulated for quantitative generalizations, and he has applied it to the notion of a mechanism. The guiding principle is that a causal relation $A \rightarrow B$ in principle permits one to change $B$ by experimentally manipulating $A$, whereas an intervention on $B$ does not lead to a change of $A$, respecting causal asymmetry. Woodward (2003) represents putative causes as variables that may take quantitative values, and possible causal relations are equations involving variables (he includes examples from physics and economics). His central notion is 'invariance under intervention,' as $A$ is a cause of $B$ only if the quantitative relation between $A$ and $B$ is invariant under some interventions on $A$. The idea is that while an intervention on $A$ changes the value of $B$, the relation among $A$ and $B$ is thereby not broken. In fact, one can change $B$ by manipulating A precisely because the causal relation is still intact. Invariant generalization is Woodward's proxy for laws of nature, as his goal is to develop an account of explanation for scientific domains where there are no laws. A universal law holds across an enormous range of conditions. A generalization may be invariant under a quite limited range of changes, but this still serves the purpose of effective causal intervention. The actual value $a$ of variable $A$ is a cause of $B$ having value $b$ even if the quantitative relation between $A$ and $B$ would only hold under a small range of counterfactual departures from value $a$. Thus, a prediction from a generalization can be an explanation if the generalization is counterfactually robust.

Let me illustrate this with an example germane to systems biology. In metabolic pathway analysis, the reaction rate of many enzymes involving one substrate behaves according to Michaelis-Menten kinetics. That is, in a reaction where substrate $S$ is turned into product $P$, the reaction rate, which is the rate of change in product concentration $[P]$, is the following function of substrate concentration $[S]$ :

$$
\frac{d[P](t)}{d t}=v_{\max } \cdot \frac{[S](t)}{K_{M}+[S](t)}
$$

The maximum reaction rate $v_{\max }$ and the Michaelis-Menten constant $K_{M}$ are constants specific to 
the type of enzyme. This equation is invariant under a substantial range of interventions on the substrate concentration, as a change in $[S]$ yields a change in the reaction rate in accordance with the above equation. While $v_{\max }$ and $K_{M}$ are formally represented as constants because one given enzyme is considered, the equation also holds if these parameters are changed, corresponding to an intervention on the enzyme's structure that changes its reaction constants. In this fashion, mathematical models from systems biology represent causal-mechanistic features. ${ }^{2}$ Woodward (2002) has likewise applied his account to mechanisms, laying out conditions "for a representation to be an acceptable model of a mechanism" (p. S375). One condition is 'modularity,' the situation where different components are independently changeable, just as [S] and $K_{M}$ in the above example. Modularity means that different variables or different equations represent non-overlapping parts of an overall causal network, so that some such parts can be changed without thereby changing other parts.

Woodward's theory offers an account of when a particular step in an overall process is causal, but not all of the causes in a system have to be represented in an individual explanation. Which aspects of a biological process that is extended across time and contains entities on several levels of organization are of explanatory relevance depends on the particular explanandum. Furthermore, while Carl Craver (2007) assumes that the explanandum phenomenon determines what the mechanism's components are and (given his ontic conception of explanation) that this fully yields what features are of explanatory relevance, I view explanations tied to various epistemic criteria of explanatory adequacy, which are explicitly or often tacitly used by scientists. There can be substantial disagreement among biologists about research agendas and the appropriateness of explanatory frameworks, reflecting epistemic assumptions that not only rule some accounts as incomplete explanations, but as failing to provide the explanatory relevant considerations altogether (Brigandt \& Love, 2010, 2012a). But

\footnotetext{
${ }^{2}$ Craver views mathematical models of limited explanatory capacity on the grounds that "Nothing in the equations ... captures the difference between mere temporal sequences and causal relationships ... mathematical dependencies cannot be equated with causal or explanatory dependency relations. The equations must be supplemented by a causal interpretation" (Craver, 2008, p. 1027). This is a bit of a straw man as a causal interpretation is always part of the mathematical model and provided by the researchers developing the model. In the below case studies from systems biology we will see that sets of equations are often developed from a prior causal network diagram.
} 
such difficulties will not be of further concern here, as for my purposes it suffices to show in the cases from systems biology considered that a particular explanandum demands in any case a mathematical model. I use the following criterion of explanatory relevance:

(ER) A component of an account representing causal features (including a mathematical equation) is explanatorily relevant, if omitting it or changing it results in an account from which the particular explanandum does not follow any longer. Features that are not explanatorily relevant for the explanandum at hand (and the criteria of explanatory adequacy) are to be excluded from the explanation.

This criterion is general and holds for any ingredient of an explanation, but let me briefly illustrate how it can make mathematical features relevant. The cycle of a eukaryotic cell consists of different phases, where various checkpoints ensure that the progression to a new phase occurs only if the important cellular processes of the current phase have been completed. On the molecular level, the cell cycle progression is regulated by the synthesis and degradation of various cyclins, resulting in oscillating levels of cyclins, which activate different kinases, and systems biologists have modeled different aspects of this. Upon cell division, the cell is in the $\mathrm{G}_{1}$ phase, which (unless the cell cycle rests by entry of a $G_{0}$ phase) is succeeded by the $S$ phase during which DNA synthesis takes place. One condition for the $G_{1}$ to $S$ phase progression is the cell having regained a particular size upon the prior cell division. Barberis et al. (2007) mathematically investigate why the underlying molecular processes result in the presence of such a critical cell size. Their model uses ordinary differential equations to captures 53 interactions in a complex network of molecular events, such as gene transcription, mRNA translation or degradation, the formation or dissociation of protein complexes, and their transport from the cytoplasm into the nucleus. On the authors' analysis, the critical cell size required for the $\mathrm{G}_{1} / \mathrm{S}$ progression is an 'emergent' property of this regulatory network. This means that this property cannot be foreseen by a consideration of the basic structure of the causal network, but only by the mathematical modeling of the network's quantitative interactions and the resulting complex dynamics, so that without such equations (and their quantitative parameters) the explanandum does not follow, making them explanatorily indispensable according to my criterion $E R$. The case studies in Section 4 analyze in more detail how mathematical models can be explanatorily relevant, and I point to several qualitative explananda that still mandate a quantitative explanation. 
In some cases precise quantitative values of a mathematical model can be explanatorily significant (e.g., if the system behavior is highly sensitive to quantitative variation in initial conditions), but criterion ER cuts both ways and entails that not every quantitative detail is relevant. If the explanandum can be derived not only given a model's precise parameter values (representing the actual quantities in nature) but still follows under a range of values, what explains is the fact that the parameter values are within a particular range, since being inside vs. outside of this range makes the difference to the explanandum (Strevens, 2008). Consequently, the second part of ER makes explicit that in such a situation a proper explanation does not adduce the precise value but the value range. A similar point holds for non-mathematical, mechanistic detail. While a mechanist like Craver (due to his focus on constitutive explanation) advocates the explanatory virtues of breaking entities into their components (Craver, 2006; Kaplan \& Craver, 2011), on my account a causal factor does not have to be broken into its lowerlevel components if the latter do not make a difference to the explanandum, so that adducing the higher-level cause suffices. Even on the same level of organization, mathematical models in systems biology often represent a relation among two entities while omitting the intermediate entities and mechanistic interactions mediating this relation. A gene regulatory network represents quantitative relations among the activity levels of different genes, without detailing intermediate entities such as mRNAs and proteins or the structure of the genes (see Section 4 for concrete examples). Arnon Levy and Bill Bechtel (2013) point out that proponents of mechanistic explanation are often biased toward concrete, mechanistic detail, and argue that they fail to appreciate the relevance of abstraction, e.g., by omitting mechanistic detail while still capturing some relevant structure of a network. In a similar vein, Levy (in press) discusses how a mathematical model can usefully abstract by aggregating the effects of many individual molecular events.

In this context, my criterion ER clarifies what is at stake. Not only is abstracting away from some molecular-mechanistic detail legitimate, if doing so does not make a difference to the explanandum, but these details ought to be omitted as they are not explanatorily relevant. Abstraction and idealization may make a model more simple and more general (in that it has more concrete instances), but the real issue is that abstraction makes a model explanatory in the first place, given that upon proper abstraction and idealization the model adduces precisely those factors that are explanatorily relevant, given the explanandum (Putnam, 1975; Strevens, 2008). 
This is at variance with Craver's (forthcoming) ontic account of explanation, as Craver states that idealization is solely an issue about representation (how well a model represents reality) but not of relevance to the issue of explanation.

\section{2. 'Predictive' models in systems biology}

Carl Craver (forthcoming) distinguishes between predictive models that do not explain and mechanistic models. Any correlation can be used for the purpose of probabilistic prediction, but this falls short of causation which is needed to underwrite explanations. Within systems biology, given the quantitative modeling context, there is indeed a good deal of talk about 'prediction,' 'predictive modeling,' and the virtues of having 'predictive frameworks.' However, in many cases what is meant is the availability of genuinely explanatory models, as a common criterion is that predictions also hold for manipulated systems, i.e., the prediction from the mathematical model (with changed parameter values or other changed features) match the features of the experimentally manipulated or otherwise modified real system. As discussed in Section 3.1, tracking the effects of (possible) manipulations is to get at causes. What many models in systems biology capture are not just manipulations at the surface, but changes of specific molecular components internal to the system, most prominently mutants whose modified genes lead to changed gene products and molecular pathways (Fisher et al., 2007). The case studies in the following section will illustrate in more detail how 'prediction' from mathematical models in systems biology often gets at the internal causal structure of biological systems and thereby offer mechanistic explanations. ${ }^{3}$

There is a reason for aiming to capture internal structure and function. For systems biology is not just curiosity driven research that aims at an intellectual understanding of nature:

The main [aim of systems biology], of course, is to understand more general principles underlying

\footnotetext{
3 “... the structure of the model should somehow reflect the underlying mechanisms in the biological system. ... In a systems biology setting, the focus is on the understanding of the underlying biological mechanisms, and not just on achieving an optimal predictor of a given system output. We have highlighted this difference through the usage of the term explanation, rather than the term hypothesis, which is the typical choice in a statistical hypothesis testing setting." (Cedersund \& Roll, 2009, pp. 904 \& 918, my emphasis)
} 
the behaviour and mechanistic workings of the complete biological systems that sustain life. ... A second aim then is the ability to understand the inner workings of particular living systems... A third aim derives from the ability to make predictions about the possible future behaviour of the system on the basis of changes we might make to our models. ... A related, fourth aim of modelling is the use of the model for technological or therapeutic purposes. (Westerhoff $\&$ Kell, 2007, p. 48)

As this quote indicates, one reason for developing explanatory models is that systems biology has medical applications in view. Enhanced therapeutic treatment (e.g., the use of drugs in cancer treatment) requires the ability to predict the effects of a particular therapeutic intervention. An understanding of a system's causal structure and operation permits the explanation of its current features (be they normal, be they pathological, in the case of a person), but it also permits inferring what the effects of a change to the system would be, including a change done for therapeutic purposes. Despite its reliance on mathematical models, systems biology is in continuity with molecular biology, where explanations are causal-mechanistic explanations and are often developed for medical and technological aims (Bechtel, this issue).

While mechanists such as Craver are worried that too many mathematical models black-box a system without representing its internal causal workings, as the we will see in the case studies below, models in systems biology are developed from a significant amount of molecularmechanistic information obtained by prior experimental research, e.g., networks that lay out the structure of causal connections among various genes and proteins, and data about quantitative interaction rates. Such models are then tested, e.g., whether they successfully predict the effects of experimental manipulations to the system, which provides clues as to whether the mathematical model needs to be refined or revised. Overall, systems biologists gain explanatory purchase precisely by developing accounts that integrate mathematical models with molecularmechanistic information, in line with the general thesis of this essay:

Computational models that reproduce and predict the detailed behaviours of cellular systems form the Holy Grail of systems biology. They require decades of work to integrate mathematicalmodelling efforts, data on molecular-interaction networks and information on the physics of cellular structures. (Kitano, 2006; see also Mogilner et al., 2012). 


\section{Cases from systems biology: qualitative explananda requiring equations}

I now present several case studies that illustrate the interplay of mechanistic explanation and mathematical modeling in systems biology. Apart from showing that such mathematical models are based on experimental data about molecular mechanisms and that they are causal by often capturing the effects of interventions internal to the system, some of the cases indicate that models in systems biology combine several levels of organization. While it is quite trivial that a quantitative explanandum (e.g., a system's precise and complete temporal dynamics) would require a quantitative account, my focus is on qualitative phenomena that necessitate an explanation involving a mathematical model. Each of the below four subsections addresses a different such qualitative explanandum.

\subsection{Bistability: apoptosis}

Not only do the cells of multicellular animals divide, differentiate, and possibly migrate, but some of them undergo apoptosis, i.e., programmed cell death. Unlike the externally inflicted death of a cell in the case of necrosis (due to toxins or trauma), which results in inflammation, apoptosis is a process controlled by this cell, involving a collapse of the cytoskeleton, the disassembly of the envelope of the nucleus, and the fragmenting of the genetic material, eventually resulting in the formation of an apoptotic body that is engulfed and destroyed by cells of the organism's immune system. Apoptosis occurs in many tissues and beyond the removal of damaged cells is in fact essential for the very formation of morphological structures in animal development (Abud, 2004). In the limbs of land vertebrates, separate digits form by initially generated soft tissue being removed in between the developing digits by means of apoptosis; and in mammals, the ducts of mammary glands are created by selective cell death. The development of the nervous system not only involves neuronal pruning, where an individual synaptic connection is eliminated, but a neuron with all its connections can be removed by apoptosis. Apoptosis is also of substantial medical relevance as the pathological occurrence of apoptosis is a factor in autoimmune diseases, ischemic damage, and neurodegenerative diseases, e.g., the apoptotic death of motor neurons in amyotrophic lateral sclerosis. Furthermore, the progression of cancer tissues is significantly enhanced by the formation of tumor cells with a defective 
apoptotic mechanism.

Due to its important role in normal development and disease, the mechanism of apoptosis has been subject to extensive experimental research (Elmore, 2007). On the molecular level, apoptosis is initiated by signaling cascades in a cell's cytoplasm involving among other things several different caspases, which are family of cysteine proteases. In response to DNA damage or lack of nutrients or oxygen, apoptosis can be triggered from within a cell starting by a signal at the mitochondria via the so-called intrinsic pathway. Apoptosis can also be triggered from the outside, as a cell may have cell surface death receptors, and when a specific ligand binds to a death receptor, inside the cell this initiates the signaling cascade of the 'extrinsic' pathway. There are interactions among these pathways, see Fig. 1 . C9 $\rightarrow \mathrm{C} 9 *$, the reaction from caspase-9 to activated caspase- 9 initiates the intrinsic pathway and $\mathrm{C} 8 \rightarrow \mathrm{C} 8 *$ initiates the extrinsic pathway, while in each case $\mathrm{C} 3 \rightarrow \mathrm{C} 3 *$ subsequently executes apoptosis.

Different aspects of the overall apoptosis mechanism have also been mathematically modeled by systems biologists (Lavrik, 2013). Some models try to capture the effects known from experimentally induced changes to a cell's apoptotic mechanism, such as the overexpression or inactivation of genes coding for proteins involved in apoptosis. Such gene products could be the target for medical therapies, if it is thereby possible to increase or decrease - depending on the medical condition - the likelihood of apoptosis execution in specific cells. Fussenegger et al. (2000) model the temporal dynamics of caspase activation using molecular data and ordinary differential equations, in the case of apoptosis triggered by both intracellular and extracellular signals. Their simulation-based predictions of whether various manipulations (including joint manipulations such as the overexpression of two genes) increase or decrease the activity of caspases executing apoptosis matches known experimental results, which increases the likelihood that this model is realistic and accounts for the causal working of the apoptosis mechanism (see Section 3.2).

The qualitative explanandum I want to focus on is bistability. Bistability is the situation where a chemical or biological system is in either of two states, where despite the possibility of switching between the two states each state is stably maintained across a range of background fluctuations internal or external to the system. In the case of apoptosis, the bistability pertains to the apoptosis state and the normal, live state of the cell. The issue is that once apoptosis is initiated, it has to be reliably terminated, since as soon as a relevant part of the cell's structure 
(e.g., its DNA) is damaged, the cell could not function properly even if apoptosis was halted. At the same time, apoptosis should be commenced in special circumstances only; so the cell's live state is to be maintained in the face of substantial noise in external and internal signals.

[Insert Fig. 1 and Fig. 2 about here. Two figures belong together and can be put next to each other (the size can be reduced), e.g., Fig. 1 above the left text column and Fig. 2 above the right text column on the same page, or Fig. 1 above Fig. 2 in one column.]

The mathematical model by Eissing et al. (2004) analyzes bistability. Based on the network of biochemical pathways downstream of the death receptor stimulus shown in Fig. 1, the researchers developed two dynamical models of the extrinsic pathway, fitting the parameters to quantities experimentally known from cell populations. The extended model uses eight ordinary differential equations to represent causal relations among eight different proteins. Fig. 2 presents one result of this modeling, depicting how $\mathrm{C}^{*}$ (activated caspase-8, which is produced in response to the stimulus from the death receptor) impacts $\mathrm{C} 3 *$ (activated caspase-3, whose presence leads to apoptosis execution). What this shows is that at low concentrations of $\mathrm{C} 8^{*}$, the concentration of $\mathrm{C} 3 *$ remains 0 , so that no apoptosis results; yet once the $\mathrm{C} 8 *$ concentration crosses a threshold, after a time-lag the $\mathrm{C} 3 *$ concentration increases fast and is maintained at a stable level, so that apoptosis is carried out. The question of why there is a $\mathrm{C} 8 *$ concentration threshold in the first place is a qualitative explanandum, as is the more general question of why a cellular system is bistable with a live and an apoptosis state. The model represents the live state in part by low $\mathrm{C} 8 *$ and $\mathrm{C} 3 *$ concentrations, and the apoptosis state by high $\mathrm{C} 8 *$ and $\mathrm{C} 3 *$ concentrations (the low and the high horizontal plateaus in Fig. 2, respectively). Beyond experimentally establishing that there is a threshold, explaining why there is a threshold requires understanding the dynamic operation among the system's components. From a non-mathematical mechanistic account - a consideration of the mechanism's structural organization and qualitative interactions as shown in Fig. 1-one cannot foresee threshold behavior. Instead, an explanation of the presence of a threshold and bistability must involve equations capturing the quantitative relations among components and the mathematical modeling of the resulting system behavior (given that the behavior is nonlinear resulting in an all-or-nothing outcome), so that my criterion $E R$ from Section 3.1 entails the equations' explanatory indispensability.

There is more to bistability analysis, as apart from accounting for how it is possible to switch from one state to the other, qualitatively different one, one needs to show that each state is 
stably maintained in the face of cellular noise. Explaining stability under a range of variation in parameter values again requires mathematical modeling. The Eissing et al. (2004) study discussed does such an analysis (for more details see Eissing et al., 2005), as do other systems biological studies of bistability in the context of apoptosis (Bagci et al., 2006; Cui et al., 2008; Ho \& Harrington, 2010). The bistability modeling by Legewie et al. (2006) includes both the extrinsic (death receptor initiated) and intrinsic (mitochondrion initiated) apoptosis pathway. Bistability is a general phenomenon, and systems biology addresses bistability in different domains, including biochemical reaction networks, cell cycle progression, cell differentiation, and cancer onset (Shiraishi et al., 2010; Wilhelm, 2009).

\subsection{Pattern formation and spontaneous symmetry breaking}

Organisms exhibit various spatial patterns, from body surface patterns such as the fur coloration of mammals or sea shell color patterns (Fig. 4, upper half) to the complex three-dimensional patterns of anatomical structures that originate during the organism's development, such as the intricately branched network of mammalian lungs. In addition to a plethora of experimental studies of developmental mechanisms, pattern formation has also been mathematically modeled (Murray, 2003; Schnell et al., 2008). Even if the explanandum phenomenon is not the overall developmental process but merely the resulting structural pattern, dynamical models are a part of the explanation. There are several different basic types of models (Morelli et al., 2012), and here I focus on a particularly prominent class of models - reaction-diffusion equations.

Reaction-diffusion systems are nonlinear partial differential equations (representing change in space in addition to time) which contain terms representing chemical reactions and terms describing the spatial diffusion of reaction products. A common subclass is activator-inhibitor systems, which have two molecular substances at their core. By means of positive feedback, the activator enhances its own production-locally increasing its concentration - and it also enhances the production of the inhibitor, which due to its higher diffusion rate acts in surrounding regions and there inhibits the production of the activator. Over time this process can lead to spatial waves of substance concentrations and the formation of stable patterns, such as regularly spaced dots or zebra stripe patterns (Murray, 2003). First proposed by Alan Turing (1952), over most of their history reaction-diffusion models have offered speculative, how- 
possibly explanations of biological pattern formation, as the underlying molecular substances and interaction properties were unknown. But nowadays experimental evidence for the presence of activator-inhibitor systems exists, for example the interaction of pigment cells in zebrafish (Nakamasu et al., 2009), palate growth in mice (Economou et al., 2012), and the regeneration of hair stem cells in mice and rabbits (Plikus et al., 2011).

[Insert Fig. 3 about here. The size can be reduced so that it does not take up more than one text column.]

A systems biology study that nicely illustrates the interplay between molecular-mechanistic research and mathematical modeling is Salazar-Ciudad and Jernvall's (2002) account of teeth development in mice and voles. The cusp number and positions of a tooth are quite distinctive, so that dentition is used as a criterion for taxonomically distinguishing different mammalian species. (Aimed at shedding light on the developmental basis of anatomical variation within and across species, the mathematical model by Salazar-Ciudad and Jernvall can generate teeth with different cusp numbers, positions, and overall shape.) Generally, teeth develop based on the signaling among epithelial and mesenchymal tissues, where the tooth crowns form from a number of epithelial signaling centers called the enamel knots. Salazar-Ciudad and Jernvall (2002) proceed from prior experimental data about relevant regulatory networks in which several genes influence each other's expression (see Fig. 3A). From this more complex causal network, a basic activator-inhibitor system is abstracted (Fig. 3B), an issue which also illustrates that a 'reaction-diffusion' model does not require that the activator and inhibitor substances directly interact as part of a chemical reaction. Instead, the activator can be a protein secreted by a cell, which binds to a receptor of adjacent cells and there triggers a signaling cascade that impacts the regulation of the gene coding for the inhibitor. (Likewise, the substance diffusion need not take place in a homogeneous medium, but can be a substance gradient across cells.) Apart from omitting the genes, mRNAs, receptors, and signaling pathways by which the activator and inhibitor proteins mechanistically interact, the model abstracts away from further intermediate entities of the causal network, e.g., the protein DAN. This omitting of molecular-mechanistic detail is licit assuming that it does not alter the functional interaction and dynamics of the activator and inhibitor. If so, by my criterion ER such for the target phenomenon explanatorily irrelevant detail ought to be excluded from the explanation (Section 3.1). Thus, a mechanistic account of how an effect is produced (citing all intermediate steps and structural interactions) and 
an explanation of why it occurs are not identical.

The labels 'activator' and 'inhibitor' pertain to the mutual influence among these two substances, but each of them can either upregulate or downregulate downstream genetic pathways, where in the present case the activator has the downstream effect of suppressing epithelial growth and inducing epithelial cells to differentiate to form an enamel knot, while the inhibitor promotes growth and suppresses knot differentiation (Fig. 3B). The computational model predicts the activator and inhibitor distributions and the three-dimensional tooth shape across time (Fig. 3C). This prediction is then compared with empirical, in vivo data (Fig. 3D). Not only does the model prediction align with the shape of developing teeth in mice, but the predicted activator and inhibitor distributions broadly conforms to the in vivo expression patterns of p21 and Fgf4, respectively, seen at different developmental stages of mice and voles, which supports the idea that the mathematical model is sufficiently realistic. In addition to gene regulation by molecular signaling, the improved model by Salazar-Ciudad and Jernvall (2010) takes into account the mechanical forces that tissues exert on cells. This model is compared to empirical data about the large variation in tooth shape found within the species of ringed seals. According to these mathematical models of tooth development, large morphological differences can often be achieved by small developmental changes. This shows that the correct mechanistic explanation of why a tooth with a certain cusp number and position develops requires the use of a mathematical model with precise parameter values.

[Insert Fig. 4 about here. The size can be reduced so that it does not take up more than one text column.]

It is less straightforward to locate a qualitative explanandum in studies on teeth development, but sea shell coloration patterns are a suitable case. These patterns develop based on stochastic factors and vary across individuals, so that the details of an individual's pattern are not a meaningful explanandum. But there are basic motifs recurring across individuals, highlighted by arrows in Fig. 4 (in the case of the species Tapes literatus). During shell growth new material is added to the outermost ridge, so that in the figure the development was from top to bottom. Two separate dark color substance waves, travelling downwards and creating two lines along the shell, will intersect where in most instances both of them continue, but occasionally only one wave survives the collision of two waves, so that two lines merge into one (uppermost arrow). Sometimes a single substance wave spontaneously splits into two waves 
(lowermost arrow in upper half of Fig. 4). There is also the situation where the wavefront suddenly breaks down along a whole ridge and a fresh pattern starts (other arrows in upper half of Fig. 4). Such basic motifs are qualitative explananda, and the activator-inhibitor model of Meinhardt (2009) is able to generate them, as shown in the lower half of Fig. 4.

A drawback of Meinhardt's (2009) models of sea shell coloration patterns is that these merely are how-possibly explanations, as the underlying molecular entities and interactions are not known. A mechanistically more realistic type of case is accounts of the development of the vertebrate limb, which has been subject to extensive experimental research, in particular in chicken. There are also mathematical models of limb skeleton development, which use reactiondiffusion equations and have been developed based on molecular data (Hentschel et al., 2004; Newman et al., 2008; Newman \& Müller, 2005). These models are able to reproduce the most generic aspects of the shape of the different bones and their relative position in the limb. Zhu et al. (2010) present a mathematical model which not only replicates the normal development of the basic skeletal features of the chicken wing, but also different instances of modified development, including the experimental removal of the (causally crucial) apical ectodermal ridge at the tip of the growing limb bud at different points in early development, and the expansion of the early limb bud either by tissue graft or as seen in two different genetic mutants. This suggests that the theoretical model gets at causal aspects of the mechanism studied, by capturing the effects of interventions internal to the system (Section 3.2). The mechanistically realistic mathematical modeling of limb skeleton development is also of medical relevance in the context of bone disorders (Newman \& Bhat, 2007).

A phenomenon of interest in the context of reaction-diffusion systems is spontaneous symmetry-breaking. Known from physics, but also of relevance in many molecular and cellular biology contexts (Li \& Bowerman, 2010a, 2010b; Soriano et al., 2009; van der Gucht \& Sykes, 2009; Weiss et al., 2003), symmetry breaking occurs when extremely small stochastic fluctuations in a system eventually lead to the crossing of a threshold that determines which of two branches of a bifurcation (in possible states of the system) is taken. Due to symmetry breaking, a reaction-diffusion system can go from a nearly homogenous state to the spontaneous emergence of a stable and distinct structural pattern. An analysis of the system's components and qualitative interactions - along the lines of the traditional philosophical vision of mechanistic explanation — could not explain how a heterogeneous pattern can be created from a homogenous 
starting point, so that equations are explanatorily indispensable in this case according to my criterion ER. This holds more generally for complete explanations of development, as one needs to account for how relatively undifferentiated tissues give rise to the highly structured anatomical patterns of organisms.

\subsection{Synchronized oscillations: the vertebrate segmentation clock}

Cellular oscillators are cells in which the expression-level of one or more genes oscillates with a regular period, resulting in corresponding oscillating concentrations of gene products. One type of case are circadian rhythms, which are oscillations with a period of about $24 \mathrm{~h}$ found in animals, plants, fungi, and even cyanobacteria. They are endogenously maintained and entrainable by outside signals (e.g., daylight). Circadian rhythms have been philosophically discussed by William Bechtel and Adele Abrahamsen, who have stressed the role of mathematical modeling (Bechtel, 2010; Bechtel \& Abrahamsen, 2010, 2011), pointing out that a quantitative model is needed to explain that the mechanism's components and organization can generate oscillations (Bechtel, 2012, this issue). Apart from highlighting that the presence of oscillations is a qualitative explanandum, I discuss a different case of cellular oscillators - the vertebrate segmentation clock - because it includes accounting for synchronized oscillations across cells and illustrates the multilevel nature of the research. (A yet further type of case is oscillations that are part of the cell cycle; for mathematical models see Ferrell et al., 2011; Yang \& Ferrell, 2013.)

Vertebrates are segmented animals, with segment numbers ranging from 30 in some fish to hundreds in snakes. In the developing, yet largely undifferentiated early embryo, distinct segments originate first as somites, which then guide the formation of vertebrae and ribs. Interestingly, individual somites develop one after the other from the embryo's head to its tail in a regular rhythm (until the species-specific number is reached). Many molecular aspects underlying somite formation have been elucidated, e.g., by the analysis of mutants with defective segment formation, with zebrafish being the best explored model organism (Dequéant \& Pourquié, 2008; Oates et al., 2012). The basic mechanism consists in the interaction of two processes: the segmentation clock consisting in synchronized cellular oscillations in the tissues where somites form, and a wavefront of a molecular substance moving with constant speed from the embryo's head to tail (where additional somites yet have to form). When the wavefront 
passes by oscillating cells, it arrests their clock at the current stage of the cycle, so that the temporal pattern of the clock is transformed into a repeated spatial molecular pattern along the embryo's longitudinal axis. Basically, when the wavefront passes by cells that happen to be at one particular point of the clock cycle, this defines the spatial boundary of the next segment to differentiate, so that segments of equal length form one after the other, where the segment length is the speed of the wavefront times period of the clock $(30 \mathrm{~min}$ in zebrafish, $2 \mathrm{~h}$ in mice, and $5 \mathrm{~h}$ in humans).

[Insert Fig. 5 about here. The size should not be reduced too much, and the figure will have to take up both text columns.]

Fig. 5 shows some of a mouse cell's components involved in generating oscillations. Even though individual studies often focus on one aspect of somite formation, ideally this research addresses several levels of organization including interaction among components on different levels. What needs to be accounted for is how molecular processes within an individual cell results in gene activity oscillations, how based on cell-cell signaling the oscillations of different cells are synchronized so as to result in the segmentation clock as the synchronized oscillation in whole tissues, and how the wavefront substance molecularly interacts with the segmentation clock so as to lead to the formation of a new segment boundary and a new somite. Some of these processes have also been mathematically modeled (Baker \& Schnell, 2009; Baker et al., 2008; Mazzitello et al., 2008; Santillán \& Mackey, 2008).

In the case of oscillations within an individual cell, mathematical models are gene regulatory network accounts that use differential equations to describe how a change in the level of mRNAs (produced by oscillating genes) impacts the concentration of proteins, some of which regulate gene transcription. While a non-mathematical mechanistic account can point to all the entities involved and their organization and qualitative interactions (whether they upregulate or inhibit one another), this is insufficient to explain the generation of oscillations, even in the case of one gene's activity. Consider the mouse gene Hes1, whose oscillating transcription has been documented by real-time imaging studies (Masamizu et al., 2006). Fig. 5 reveals that the protein produced by Hes1 inhibits the expression of Hes1, so that there is a quite direct negative 
feedback loop. ${ }^{4}$ One can imagine how a negative feedback loop can produce oscillations, however, whether the period of the oscillation remains constant and whether feedback results in damped oscillations that fade out or in sustained oscillations depends on the interaction parameters, so that the explanation has to involve some of this quantitative detail. And one has to explain why Hes1 oscillates in its actual mechanistic context, which beyond the presence of one feedback loop includes several other genes influencing the transcription of Hes1 (Fig. 5). Predicting the effect of network interactions - and thus explaining why Hes1 regularly oscillates - is impossible without the analysis of a mathematical model. Indeed, many of a mouse cell's genes oscillate, where the genes of the FGF pathway and of the Notch pathway all oscillate in phase, while the different genes of the Wnt pathway (see Fig. 5) are in antiphase to this (Dequéant et al., 2006). This phenomenon likewise requires a mechanistic explanation involving a mathematical account. Goldbeter and Pourquié (2008) offer such a quantitative model of the synchronization among the FGF, Notch, and Wnt pathways.

A further question is why the oscillations of different cells are in synchrony. One ingredient of the mechanism is cell-cell signaling by means of the Notch receptor, but an explanation of synchronization necessitates a mathematical treatment. Many such mathematical models are phase oscillator models, which treat each cell as one oscillator with a certain phase, abstracting away from the complex details of how the oscillation is generated within each cell (so that the model need not know about some of the complex mechanism and interaction quantities within a cell). The model represents how the phases of different cells influence each other with a timedelay, showing that the interaction among adjacent cells results on overall synchrony among all cells (Morelli et al., 2009). On my account, abstracting away from such internal mechanistic workings of cells is legitimate, and even required to capture only those features that are explanatory, if the explanandum is the synchronization but not the generation of oscillations (Section 3.1). Mathematical modeling can go in hand with experimental studies manipulating the

\footnotetext{
${ }^{4}$ Fig. 5 is quite schematic and shows the four oscillating genes Hes1, Hes5, Hes7, and Hey2 (all of which engage in negative feedback) together. Likewise, the proteins produced from some genes (dark ovals and rectangles to the right of mRNAs) are depicted within the nucleus, even though they are actually generated in the cytoplasm. So for a protein such as HES1 to inhibit a gene's expression, it first has to be transported from the cytoplasm into the nucleus (Oates et al., 2012).
} 
synchronization mechanism, e.g., changes to the timing of Delta-Notch signaling, where the mathematical model is able to capture the effects of such an experimental perturbation (RiedelKruse et al., 2007). The phase oscillator model of Herrgen et al. (2010) predicted how the segmentation clock period would change in a novel zebrafish mutant, a prediction that was borne out upon the creation of the mutant. Such borne out prediction about experimental interventions internal to the system increase the plausibility that the models capture actual causal structure (Section 3.2). From experimental studies it is known that individual oscillating cells move so as to change their relative positions, and that synchronization is recovered upon perturbation that initially destroy synchrony. Uriu et al. (2010) mathematically show that synchronization can be maintained under random cell movement, and that such movement actually reduced the timespan of reestablishing synchrony following perturbation.

The questions of why a gene's activity shows sustained oscillations of a regular period, why several of a cell's genes oscillate in phase or antiphase, why the oscillations across cells are synchronized, and why embryonic segments of equal length develop are all qualitative explananda. I have argued that knowledge of the mechanism's components and their qualitative interactions is insufficient to predict that regular oscillations will occur. ${ }^{5}$ In line with my criterion $E R$ the mechanistic explanation must include equations that model the system's dynamic behavior resulting from quantitative interactions in the actual, complex network so as to show that oscillations result. Accounting for why the oscillation has a particular period in a certain species (e.g., 120min in mice) likewise requires a quantitative explanation.

\subsection{Robustness, a distributed functional process}

Robustness is a biological system's property to maintain some of its features and functioning

\footnotetext{
${ }^{5}$ Robins and Craver (2009) discuss oscillations in the analogous context of circadian rhythms. Even though they indicate that the "aspects of the circadian rhythm phenomenon that must be accounted for by any adequate and complete explanation" includes "the intrinsic timing of the clock" (p.44), their mechanistic account merely mentions entities, activities, and their organization (including feedback loops and duration of steps). While the mechanism's components and organization — as features in nature — do ontologically bring about the phenomenon to be explained (oscillations), Robins and Craver neglect that a mechanistic explanation must epistemically show how (or at least that) the explanandum follows - be it by mentally simulating the operation or in this case by mathematical analysis.
} 
despite modifications internal or external to the system (Kitano, 2004a). Often robustness is not an accidentally present, passive happening, but an evolved ability where the organismal system actively responds to disturbances, so as during embryonic development to permit the reliable generation of the adult phenotype in the face of perturbations to development, and subsequently to maintain functioning and an adaptive phenotype in a changing environment. To be sure, also tumor tissues can acquire robustness so as to not to respond to cancer therapies, making the study of robustness medically relevant (Kitano, 2004b). There is also robustness to genetic modifications. While this is most commonly known from experimental knockout studies, where the deactivation of a gene implicated in a molecular pathway surprisingly does not yield a changed phenotype, robustness to genetic change is also of evolutionary significance, as it enhances the accumulation of genetic variation within populations (for a discussion of the evolutionary role of robustness see Brigandt, in press). Robustness occurs on various levels of organization, from the genetic code and the structure of RNAs and proteins, up to more complex organismal subsystems (Wagner, 2005b). Individual metabolic pathways and larger metabolic networks can be robust in that the overall metabolic flux is maintained even if the reaction rate of individual enzymes is significantly decreased. In the case of a robust gene regulatory network, its low-level phenotypic product, for instance a spatial pattern of signaling molecules across tissues (eventually giving rise to anatomical structures), forms regardless of whether some the network's genes are altered or deactivated.

While experimental studies are a major tool to show a system's robustness (Baggs et al., 2009 use small interfering RNAs to influence the expression of various genes), mathematical modeling can also be helpful. Exhaustively demonstrating that a system is robust to changes in several components - each across a given range — would require that all possible component state combinations be considered. It is not feasible to experimentally produce all these modified systems, but in a mathematical model different factors can be independently varied to a quantitative degree and one can analyze the effect of any number of modifications. Beyond showing that a system exhibits robustness, the issue of interest given the main thesis of my paper is that in many cases the explanation of why the system is robust necessitates a mathematical account. A system's robustness in some properties with respect to certain modifications can count as a qualitative phenomenon to be explained (at least the explanandum is not the temporal change in all of the system's quantitative properties). Some mathematical approaches attempt to 
infer a network's robustness from the topology of causal relations (Barabási \& Oltvai, 2004). A network of the scale-free type, where there are few nodes with many connections, is likely to be robust to the elimination of individual nodes (Greenbury et al., 2010; Jeong et al., 2000). However, often the biological impact of modifications cannot be inferred from gene network topology alone, so that an actual explanation of robustness involves the dynamical modeling of the perturbed system's behavior based on experimental data about quantitative interactions and gene function rates (Siegal et al., 2007).

Here are some systems biology studies of robustness that integrate mathematical modeling and experimentally obtained mechanistic information. In some unicellular organisms whose genome has been sequenced and molecular functioning has been well-characterized, including the bacterium Escherichia coli and the eukaryotic yeast Saccharomyces cerevisiae, the robustness of metabolic networks has been mathematically modeled (Edwards \& Palsson, 1999, 2000a; Smart et al., 2008). Edwards and Palsson (2000b) show that the rate of two different enzymatic reactions in E. coli can be reduced to $15 \%$ and $19 \%$, respectively, of the optimal rate, without significantly diminishing the system's overall metabolic flux (whereas upon further individual reaction rate reduction the system's flux drops rapidly). In contrast, for a third reaction, the threshold rate above which overall metabolic flux is largely unaffected is $70 \%$. $\mathrm{A}$ quantitative explanation has to be given as the system's response to change (with changes to different reactions having a different impact) depends, among other things, on the quantitative rates of the various reactions in the metabolic network.

The nematode Caenorhabditis elegans is among the six most prominent animal model organisms. The vulva (in hermaphrodites) is known to develop in a robust fashion. While the laser ablation of individual cells was one of the first experimental methods for investigating the impacts of developmental perturbations, nowadays accounts of the robustness of vulva development can rely on data about molecular pathways and signaling networks (Braendle \& Félix, 2008; Milloz et al., 2008). Based on information about gene interactions, Fisher et al. (2007) present a mathematical model of vulva development, which is additionally supported by the subsequent experimental verification of two model-derived predictions (one of which is about a mutant and thus an experimental intervention). The computational model sheds light on the mechanistic basis of stable cell fate patterns which underlie robust development.

As is well-known, many experimental studies of the fruit fly Drosophila melanogaster 
pertain to the molecular interactions and networks involved in the formation of the basic body axes and the different body segments in early embryonic development. One instance of robustness is the segment polarity gene network, which determines in each body segment its anterior and posterior end, by different genes being expressed in different parts of a segment. The classical study by von Dassow et al. (2000) mathematically modeled this mechanism involving 48 interaction parameters representing such features as gene transcription rates, decay rates of gene products, and the degree of cooperative interaction among entities jointly affecting gene transcription. Their analysis shows that a functional network results in about $90 \%$ of random interaction parameter value assignments, so that the gene regulatory system is robust to a large number of modifications. More recent accounts incorporate additional molecular detail into their quantitative models to yield clues about different mechanistic aspects underlying the robustness of the segment polarity network (Albert \& Othmer, 2003; von Dassow \& Odell, 2002). The mathematical model of Ingolia (2004) yields that the segment polarity gene expression pattern to be eventually produced forms a stable steady state that is due to the presence of distinct expression states for each cell, corresponding to different cell types. (Such distinct, stable cell states are an instance of bistability, which was discussed in Section 4.1.) Positive feedback among components - which is a qualitative, topological property of a gene regulatory network - is a necessary condition for the existence of distinct stable states. Ingolia, however, argues that feedback topology is not sufficient, as different stable states are present only if the interaction parameters satisfy certain inequalities. Thus the explanation of robustness has to include quantitative information about the interactions of gene network components.

An earlier step of Drosophila segment formation involves gap genes, each of which defines a larger region of the embryo (by being expressed therein), where the deactivation of a gap gene results in the corresponding body segment's loss (resulting in a 'gap'). The mathematical model of the gap gene regulatory network by Manu et al. (2009a, 2009b) is based on and tested by data from high precision gene expression studies. It explains the robustness of gap gene pattern formation by showing that gap gene expression patterns form dynamical attractors, i.e., states toward which the system evolves and tends to return to even if temporarily removed from such an attractor state by perturbation. (For a review of mathematical models pertaining to different aspects of Drosophila spatial patterning and segmentation see Umulis et al. 2008.)

In some instances robustness results from redundancy, where two copies of a structure are 
present so that the loss of one structure does not have any impact (Dean et al., 2008). But even in the case of a duplicated gene, there often have to be functional amendments, as an active mechanism has to turn on the second gene copy which is normally not expressed (Baggs et al., 2009; Kafri et al., 2005). Usually robustness is not just due to structural redundancy, but is a distributed functional process in that the overall system undergoes various functional changes to compensate for the loss of one component (Ihmels et al., 2007; Wagner, 2005a, 2005b). A case in point are such gene regulatory networks where the inactivation of one gene leads to compensatory function changes in several other genes of the network, which can be due to the network containing several feedback loops so as to buffer against perturbations (Li et al., 2009). Another way of obtaining distributed robustness is by means of exploratory behavior, in which several of a system's parts search for their target (Kirschner \& Gerhart, 2005). An example is how the individual shape of a eukaryotic cell is produced by each of the many microtubules growing and shrinking in an exploratory fashion, until some of their lengths are stabilized by a signal from without the cell. Exploratory behavior yields robustness, as even in the case of a disturbance the target will eventually be found, and it is a process whose functioning is distributed throughout a system. In many instances of distributed robustness, how a single perturbation results in the actual system-wide response (which has to be considered to understand why the robust feature is still produced) cannot be explained without a consideration of the complex system's various interactions and the resulting system functioning, which makes a mathematical model necessary.

In Section 3.1, I indicated that the reductive decomposition of a mechanism's component is not always required. If the component is explanatorily relevant_-if changing it would lead to a change in the surrounding mechanism's features to be explained-but the component's lowerlevel constituents do not make a difference to the particular explanandum, then according to my criterion ER the explanation should cite the component but not its constituents. The component exhibiting robustness is a clear way in which this can be the case, as a change in the component's constituents does not make a causal difference to the component's robust property (that is relevant to the explanation). In addition to the points on explanation (e.g., the indispensability of quantitative modeling) made so far, the next section will use robustness and distributed system functioning to draw some lessons for philosophical views on the nature of mechanisms. 


\section{Toward a broader conception of mechanisms and explanation}

Apart from illustrating how models in systems biology are developed based on and tested by molecular-mechanistic data, my case studies have focused on the explanatory relevance of mathematical models. Before returning to this and offering more general philosophical remarks on explanation, I extract points from the cases that mandate a broader philosophical conception of mechanisms. These may well be features that philosophers would not object to (and that biologists naturally take to be aspects of mechanisms), but they point to the drawbacks of stereotypical philosophical characterizations of what a mechanism is and highlight issues in need of more detailed philosophical investigation.

\subsection{Mechanisms}

Philosophers focus on a mechanism's qualitative organization and its component's qualitative activities, e.g., binding, opening, activating (Bechtel, 2011; Boogerd et al., 2007a). Yet the components of mechanisms have quantitative properties and undergo quantitative changes. This is obvious in such biochemical cases as the concentration of a metabolite and the specific reaction rate of an enzyme, but even the activity of a gene is not an all-or-none affair, but a gene produces a certain number of transcripts per unit of time. How a gene's transcription rate differs across cells or changes within a cell across time is experimentally measured by genome-wide and real-time expression studies and was of theoretical relevance to the different models of gene regulatory networks mentioned throughout Section 4. In fact, several transcription factors may jointly influence the activity of one gene, where such cooperative interaction can transform a transcription factor concentration to gene expression rate curve that is shallow (for a single transcription factor binding) into a threshold-like curve where quantitative differences yield a qualitative effect (Wang et al., 2009). A quantitative change in cell-cell signaling resulting in a qualitative cellular response is one basis for the complexity of cellular and developmental processes. My case studies have also pointed to other instances where quantitative features matter to the properties resulting from system behavior.

A pictorial representation of a mechanism may suggest that it consists of a fixed stock of entities (that move and interact), but one should not neglect the disappearance of entities and the 
generation of novel entities as characteristics of a mechanism. Many components of a mechanism are transient, with biochemical reactions rapidly transforming one molecule into a different kind of molecule and breaking down entities into smaller molecular components. (Baetu, in press, points out that a system's functioning is not so much due to the stable presence of entities, but to shortlived molecules that are replaced by molecules of the same type.) Apoptosis illustrates that even entities above the molecular level such as whole cells can vanish during the operation of a mechanism. As mentioned in Section 4.1, the controlled death of cells and removal of particular tissues is instrumental in the formation of anatomical structures during normal development. Conversely, apart from new activities and behaviors being produced (e.g., gene activity oscillations), new structures, even a new type of structural entity can be generated within a mechanism. Some biochemical and molecular processes result in a new kind of protein internal to a cell; and cell division followed by cell differentiation can generate a novel cell type.

When a mechanism's operation is described as consisting of "regular changes from start or set-up to finish or termination conditions," where "what makes [the mechanism] regular is the productive continuity between stages ... represented schematically by $\mathrm{A} \rightarrow \mathrm{B} \rightarrow \mathrm{C}$ " (Machamer et al., 2000, p.3), such a stereotypical characterization creates the impression that every mechanism consists in a single, linear causal sequence. To be sure, causal pathways may branch or merge, and in fact form complex networks of interactions among various components. Molecular biologists have come to recognize the importance of this, as witnessed by discussions of 'gene regulatory networks' and the recent terminological shifts from 'metabolic pathway' to 'metabolic network' and from 'signaling pathway' to 'signaling network.' Many researchers emphasize that since there is 'cross-talk' between what deemed to be separate pathways, the larger network needs to be studied (Barabási et al., 2011; Fraser \& Germain, 2009; Jørgensen \& Linding, 2010; Layek et al., 2011; Wing et al., 2011). Furthermore, the organization of causal interactions is not unidirectional and acyclic, but mechanisms have feedback loops (Bechtel, 2011). This complex topology of causal and functional relations has to be taken into consideration because it is crucial for the mechanism's actual behavior and the resulting higher-level properties. In the above case studies, we have seen feedback loops to be vital for activator-inhibitor systems producing particular spatial patterns (Section 4.2), the generation of regular genetic oscillations (4.3), and the robustness of many gene regulatory networks (4.4).

While philosophical accounts have centered on the structural and spatial aspects of 
mechanisms, such as the structure of interacting components and their spatial organization, my discussion has highlighted the functional aspects of mechanisms, which are of utmost importance to systems biology. There is distributed functionality, where a biological system is not controlled by a limited number of privileged entities or activities, but where the dynamics of how the system behaves and is functionally regulated is of a more holistic nature (Krohs \& Callebaut, 2007; Moreno, 2007; Westerhoff \& Kell, 2007). ${ }^{6}$ Section 4.4 discussed that robustness is often a distributed process, for instance when a gene's activity is part of a gene regulatory network, yet the deactivation of this gene does not make a difference to the network operation's final outcome, due to compensatory changes to the activities of other genes throughout the network. This raises problems for philosophical accounts that assume that a mechanism can be broken into separate components (Mitchell, 2009). James Woodward (2002, 2003) lays out the condition of modularity as the in principle possibility of manipulating one component without impacting the behavior of others (see Section 3.1). Yet a system with distributed functionality does not exhibit modularity in the strict sense. Carl Craver (2007) extends Woodward's notion to even define what the components of a mechanism are, where something is a component only if manipulating it would make a difference to the mechanism's characteristic feature. But in the case of a robust gene regulatory network, changing the structure or activity of individual genes does not make such a difference - and without components there is no mechanism by the lights of standard philosophical accounts. Of course one can distinguish different genes as different structures, but the issue at hand is the (separable) functional contributions of mechanism components. What the phenomena of distributed functionality and robustness show is that sometimes the components of a mechanism cannot be clearly individuated (which also entails that the boundary between the mechanism and entities not belonging to the mechanism is blurry).

For the simple reason that a mere how-possibly mechanistic account does not actually explain (Craver, 2006, 2007), philosophers have focused on the actual organization and the actual, regular operation of a mechanism. But there are also dispositional properties of a mechanism. A case in point is robustness, which pertains to how the mechanism would respond

\footnotetext{
${ }^{6}$ In metabolic pathways without any bifurcations, the sum of all flux control coefficients is one, so that even in such a simple linear system a change in the reaction control at one step entails reaction rate changes at other steps / enzymes (Fell, 2007).
} 
upon perturbation. Michael Behe's (1996) 'intelligent design argument' against evolution relies on the notion of irreducibly complex molecular systems, which are systems where the removal of any part leads to the system ceasing to function (Brigandt, 2013b, in press). Robustness is the opposite of irreducible complexity; and apart from showing Behe's vision of the nature of molecular systems to be misguided, robustness more generally highlights the flexibility and adaptability of many biological mechanisms. Thus, beyond the actual organization and operation of a mechanism, properties of a mechanism to be taken into consideration by philosophers include the mechanism's modified organization and modified operation.

\subsection{Explanation}

Robustness is not only a property of some systems, but an issue that research in systems biology deems in need of study and explanation. This bring is us from the ontology of mechanisms to the epistemological topic of explanation. In the case studies I have argued that there are even qualitative explananda about mechanisms whether the explanation must include quantitative information or at least mathematical models. The qualitative phenomena discussed were bistability (Section 4.1), spontaneous symmetry breaking and qualitative aspects of spatial patterns (4.2), regular oscillations and synchronized oscillations (4.3), and robustness (4.4). There are two related reasons for why mathematical modeling is needed. First, according to my criterion $E R$ from Section 3.1, if omitting features from a mechanism representation does not entail the explanandum any longer, or if changing some features implies different system properties than the ones to be explained, then those features must be included in the explanation. Sometimes such explanatorily relevant features can only be computationally or mathematically represented, for example, if the complex topology of an interaction network is explanatorily relevant, or if system behavior is sensitive to quantitative parameters (Section 4 presented several examples of this). Second, beyond representing the different ingredients of a mechanism - the entities, activities, and their organization - an explanation has to show how (or at least that) the explanandum phenomenon results from this. Mental simulation is typically unable to track the causal effects of complex feedback loops or the impact of nonlinear interactions, so computer simulation or the mathematical analysis of a model is indispensable for the explanation. Systems biologists may emphasize 'emergent properties' (Bhalla \& Iyengar, 1999; Boogerd et al., 2005; 
Boogerd et al., 2007a; Ihekwaba et al., 2005; Westerhoff \& Kell, 2007). This does not presuppose a strong ontological notion of emergence, and rather means that a system's qualitative properties arise only upon the dynamic operation of the system and that these qualitative features cannot be foreseen from the complex system's components and their basic interactions (Mitchell, 2012). This type of emergence still is scientifically important as it entails the need to study the mechanism's complete organization — not just its structural, but also its functional organization — and to use a mathematical account.

While emphasizing that models in systems biology are developed from molecular data, my case studies also indicated that such models abstract away from a good deal of mechanistic detail. Many models in systems biology describe functional relations among entities, without representing their structure, which is the case if the focus is on the impact of system functioning and not on how individual functions are brought about by the structure of molecular entities. Moreover, a gene regulatory network model captures how a gene's expression changes as a function of other genes' activity, but omits the mechanistic entities and activities mediating this, e.g., mRNAs and proteins. According to criterion ER, this is legitimate if omitting these features makes no difference to the dynamics of the system modeled, or at least no difference to the outcome of the system's operation to be explained. In fact, explanatorily non-relevant features should be excluded, so that such idealization is mandated and makes the model explanatory in the first place. This position is at variance with Carl Craver's (forthcoming), who deems idealization to be an issue about representation (how realistic a description is), but irrelevant to explanation.

Many contemporary philosophers accept a pluralism about the types of explanation (Brigandt, 2013a). The criticism of the deductive-nomological model did not lead to its replacement by a single model of explanation. In addition to causal-mechanistic explanations known from molecular and experimental biology, philosophers may acknowledge that there are explanations based on mathematical models, for instance as found in evolutionary biology and ecology. Different types of explanation need not be relegated to different disciplines (pace Winther, 2006). Mechanistic types of explanation in terms of physical parts and explanations using mathematical models can be found in molecular biology, and systems biology shows that there are even individual explanations that combine both types of explanation, enhancing the plurality among the kinds of explanations. 
Individual explanations can be very complex. In actual science explanatory contributions are continuously added to the overall account, which can often be deemed to be complete only relative to criteria of explanatory adequacy that have been chosen in a certain context so as to address only some aspects of a complex phenomenon (Brigandt \& Love, 2012a). Furthermore, an overall explanation can consist of a plethora of explanatorily relevant items of knowledge. These can pertain to different levels of organization (being provided by different scientific fields), with some being empirical data and other more theoretical accounts. Some of the explanatory components can be of a quite different type, for example, structural knowledge about physical entities as well as mathematical equations about functional dynamics. For such reasons, one lesson is that some explanatory accounts are so complex that they do not consist in and cannot be captured by a single representation. It may thus be better to speak of an overall explanatory account or framework than of one explanation. The deductive-nomological and related models of explanation assumed that an explanation consists of two sets of statements, the explanans and the explanandum, that stand in a certain relation (Hempel, 1965; Hempel \& Oppenheim, 1948). While such a philosophical theory of explanation aimed at laying out conditions for what makes a set of statements an explanans, the complexity of explanatory accounts in science shows in my view that no such simple philosophical account is possible.

In my argument that certain mathematical models from system biology are explanatory I heeded Craver's (2007) admonition that not every representation or prediction is an explanation. However, this does not entail that explanation can be treated independently of other epistemological notions such as description, prediction, scientific inference, and confirmation. For philosophy of science has moved away from exclusively studying the content of science, and come to address discovery and the practice of science (Brigandt, 2013a, 2013b). And in their practice, biologists use different representations and pursue different scientific aims in combination (Green, 2013). While some mathematical models are not meant to be explanatory and merely describe, a single model may well be developed and used for many purposes at the same time: description, prediction, discovery, and explanation. A model with explanatory capacity may also describe relations among data with as high a degree of precision (and mathematical simplicity) as possible. Its predictions can be used to test a hypothesis, so as to serve the purpose of confirmation. But it can also be used for heuristic and practical functions, as the analysis of a modeled system's behavior may reveal unforeseen results, so as to open new 
conceptual spaces or to provide guidelines for the next steps in experimental discovery (Wimsatt, 2007). One representation may be used for explanatory and other scientific purposes, but even in their research geared toward the generation of an explanatory account, scientists make use of many individual representations, some of which are non-explanatory. Since the scientific activity of explaining is related to other activities such as predicting, confirming, modeling, and choosing theoretical and experimental strategies, philosophers cannot study discovery, confirmation, and explanation in isolation from each other. Since in scientific practice, explanations and other representations are jointly used, philosophical theories of explanation have to be related to other epistemological notions, including description, prediction, standard, and method.

\section{Acknowledgements}

I am indebted to Bill Bechtel, Arnon Levy, Maureen O'Malley, and an anonymous referee for detailed comments on previous versions of this paper. Fig. 1 and 2 are reprinted from Eissing et al. (2004) with the permission of the copyright holder, the American Society for Biochemistry and Molecular Biology. Fig. 3 is reprinted from Salazar-Ciudad and Jernvall (2002) with the permission of the copyright holder, the National Academy of Sciences, USA. Fig. 4 is reprinted from Meinhardt (2009) with the kind permission from Springer Science+Business Media BV. Fig. 5 is reprinted from Dequéant and Pourquié (2008) by permission from Macmillan Publishers Ltd.

\section{References}

Abud, H. E. (2004). Shaping developing tissues by apoptosis. Cell Death \& Differentiation, 11, 797-799.

Albert, R., \& Othmer, H. G. (2003). The topology of the regulatory interactions predicts the expression pattern of the segment polarity genes in Drosophila melanogaster. Journal of Theoretical Biology, 223, 1-18.

Alon, U. (2007). An introduction to systems biology: Design principles of biological circuits. Boca Raton: Chapman \& Hall / CRC Press. 
Baetu, T. (in press). From mechanisms to mathematical models and back to mechanisms: Quantitative mechanistic explanations. In C. Malaterre \& P.-A. Braillard (Eds.), Explanation in biology: An enquiry into the diversity of explanatory patterns in the life sciences. Berlin: Springer.

Bagci, E. Z., Vodovotz, Y., Billiar, T. R., Ermentrout, G. B., \& Bahar, I. (2006). Bistability in apoptosis: Roles of Bax, Bcl-2, and mitochondrial permeability transition pores. Biophysical Journal, 90, 1546-1559.

Baggs, J. E., Price, T. S., DiTacchio, L., Panda, S., FitzGerald, G. A., \& Hogenesch, J. B. (2009). Network features of the mammalian circadian clock. PLoS Biology, 7, e1000052.

Baker, R. E., \& Schnell, S. (2009). How can mathematics help us explore vertebrate segmentation? HFSP Journal, 3, 1-5.

Baker, R. E., Schnell, S., \& Maini, P. K. (2008). Mathematical models for somite formation. In S. Schnell, P. K. Maini, S. A. Newman, \& T. J. Newman (Eds.), Multiscale modeling of developmental systems (pp. 183-203). New York: Academic Press.

Barabási, A.-L., Gulbahce, N., \& Loscalzo, J. (2011). Network medicine: A network-based approach to human disease. Nature Reviews Genetics, 12, 56-68.

Barabási, A.-L., \& Oltvai, Z. N. (2004). Network biology: Understanding the cell's functional organization. Nature Reviews Genetics, 5, 101-113.

Barberis, M., Klipp, E., Vanoni, M., \& Alberghina, L. (2007). Cell size at S phase initiation: An emergent property of the $\mathrm{G}_{1} / \mathrm{S}$ network. PLoS Computational Biology, 3, e64.

Bechtel, W. (2006). Discovering cell mechanisms: The creation of modern cell biology. Cambridge: Cambridge University Press.

Bechtel, W. (2010). The downs and ups of mechanistic research: Circadian rhythm research as an exemplar. Erkenntnis, 73, 313-328.

Bechtel, W. (2011). Mechanism and biological explanation. Philosophy of Science, 78, 533-557.

Bechtel, W. (2012). Understanding endogenously active mechanisms: A scientific and philosophical challenge. European Journal for Philosophy of Science, 2, 233-248.

Bechtel, W. (this issue). From molecules to behavior and the clinic: Integration in chronobiology. Studies in History and Philosophy of Biological and Biomedical Sciences. doi:10.1016/j.shpsc.2012.10.001

Bechtel, W., \& Abrahamsen, A. (2005). Explanation: A mechanist alternative. Studies in History and Philosophy of Biological and Biomedical Sciences, 36, 421-441.

Bechtel, W., \& Abrahamsen, A. (2010). Dynamic mechanistic explanation: Computational modeling of circadian rhythms as an exemplar for cognitive science. Studies in History and Philosophy of Science, 41, 321-333.

Bechtel, W., \& Abrahamsen, A. (2011). Complex biological mechanisms: Cyclic, oscillatory, and autonomous. In C. Hooker (Ed.), Philosophy of complex systems (pp. 257-285). Amsterdam: Elsevier. 
Bechtel, W., \& Richardson, R. C. (1993). Discovering complexity: Decomposition and localization as strategies in scientific research. Princeton: Princeton University Press.

Behe, M. J. (1996). Darwin's black box: The biochemical challenge to evolution. New York: Free Press.

Bhalla, U. S., \& Iyengar, R. (1999). Emergent properties of networks of biological signaling pathways. Science, 283, 381-387.

Bogen, J. (2005). Regularities and causality; generalizations and causal explanations. Studies in History and Philosophy of Biological and Biomedical Sciences, 36, 397-420.

Boogerd, F. C., Bruggeman, F., Richardson, R., Stephan, A., \& Westerhoff, H. (2005). Emergence and its place in nature: A case study of biochemical networks. Synthese, 145, 131-164.

Boogerd, F. C., Bruggeman, F. J., Hofmeyr, J.-H. S., \& Westerhoff, H. V. (2007a). Towards philosophical foundations of Systems Biology: Introduction. In F. C. Boogerd, F. J. Bruggeman, J.-H. S. Hofmeyr, \& H. V. Westerhoff(Eds.), Systems biology: Philosophical foundations (pp. 3-19). Amsterdam: Elsevier.

Boogerd, F. C., Bruggeman, F. J., Hofmeyr, J.-H. S., \& Westerhoff, H. V. (Eds.). (2007b). Systems biology: Philosophical foundations. Amsterdam: Elsevier.

Braendle, C., \& Félix, M.-A. (2008). Plasticity and errors of a robust developmental system in different environments. Developmental Cell, 15, 714-724.

Brigandt, I. (2010). Beyond reduction and pluralism: Toward an epistemology of explanatory integration in biology. Erkenntnis, 73, 295-311.

Brigandt, I. (2013a). Explanation in biology: Reduction, pluralism, and explanatory aims. Science \& Education, 22, 69-91.

Brigandt, I. (2013b). Intelligent design and the nature of science: Philosophical and pedagogical points. In K. Kampourakis (Ed.), The philosophy of biology: A companion for educators (pp. 205-238). Berlin: Springer.

Brigandt, I. (in press). Evolutionary developmental biology and the limits of philosophical accounts of mechanistic explanation. In P.-A. Braillard \& C. Malaterre (Eds.), Explanation in biology: An enquiry into the diversity of explanatory patterns in the life sciences. Berlin: Springer.

Brigandt, I., \& Love, A. C. (2010). Evolutionary novelty and the evo-devo synthesis: Field notes. Evolutionary Biology, 37, 93-99.

Brigandt, I., \& Love, A. C. (2012a). Conceptualizing evolutionary novelty: Moving beyond definitional debates. Journal of Experimental Zoology Part B: Molecular and Developmental Evolution, 318, 417-427.

Brigandt, I., \& Love, A. C. (2012b). Reductionism in biology. In E. N. Zalta (Ed.), The Stanford Encyclopedia of Philosophy. http://plato.stanford.edu/entries/reduction-biology

Bruggeman, F. J., Westerhoff, H. V., \& Boogerd, F. C. (2002). BioComplexity: A pluralist 
research strategy is necessary for a mechanistic explanation of the "live" state. Philosophical Psychology, 15, 411-440.

Cedersund, G., \& Roll, J. (2009). Systems biology: Model based evaluation and comparison of potential explanations for given biological data. FEBS Journal, 276, 903-922.

Craver, C. F. (2005). Beyond reduction: Mechanisms, multifield integration and the unity of neuroscience. Studies in the History and Philosophy of Biological and Biomedical Sciences, 36, 373-395.

Craver, C. F. (2006). When mechanistic models explain. Synthese, 153, 355-376.

Craver, C. F. (2007). Explaining the brain: Mechanisms and the mosaic unity of neuroscience. Oxford: Oxford University Press.

Craver, C. F. (2008). Physical law and mechanistic explanation in the Hodgkin and Huxley model of the action potential. Philosophy of Science, 75, 1022-1033.

Craver, C. F. (forthcoming). Explanation: The ontic conception. In A. Hütteman \& M. Kaiser (Eds.), Explanation in the biological and historical sciences. Berlin: Springer.

Craver, C. F., \& Darden, L. (Eds.). (2005). Mechanisms in biology. Special issue of Studies in History and Philosophy of Biological and Biomedical Sciences (Volume 36, Issue 2).

Crawford, J. W., Harris, J. A., Ritz, K., \& Young, I. M. (2005). Towards an evolutionary ecology of life in soil. Trends in Ecology and Evolution, 20, 81-87.

Cui, J., Chen, C., Lu, H., Sun, T., \& Shen, P. (2008). Two independent positive feedbacks and bistability in the Bcl-2 apoptotic switch. PLoS ONE, 3, e1469.

Darden, L. (2005). Relations among fields: Mendelian, cytological and molecular mechanisms. Studies in History and Philosophy of Biological and Biomedical Sciences, 36, 349-371.

Darden, L., \& Maull, N. (1977). Interfield theories. Philosophy of Science, 44, 43-64.

Davidson, E. H. (2006). The regulatory genome: Gene regulatory networks in development and evolution. London: Academic Press.

Davidson, E. H., \& Erwin, D. H. (2006). Gene regulatory networks and the evolution of animal body plans. Science, 311, 796-800.

Dean, E. J., Davis, J. C., Davis, R. W., \& Petrov, D. A. (2008). Pervasive and persistent redundancy among duplicated genes in yeast. PLoS Genetics, 4, e1000113.

Dequéant, M.-L., Glynn, E., Gaudenz, K., Wahl, M., Chen, J., Mushegian, A., \& Pourquié, O. (2006). A complex oscillating network of signaling genes underlies the mouse segmentation clock. Science, 314, 1595-1598.

Dequéant, M.-L., \& Pourquié, O. (2008). Segmental patterning of the vertebrate embryonic axis. Nature Reviews Genetics, 9, 370-382.

Economou, A. D., Ohazama, A., Porntaveetus, T., Sharpe, P. T., Kondo, S., Basson, M. A., Gritli-Linde, A., Cobourne, M. T., \& Green, J. B. A. (2012). Periodic stripe formation by a Turing mechanism operating at growth zones in the mammalian palate. Nature Genetics, 44 , 348-351. 
Edwards, J. S., \& Palsson, B. O. (1999). Systems properties of the Haemophilus influenzae Rd metabolic genotype. Journal of Biological Chemistry, 274, 17410-17416.

Edwards, J. S., \& Palsson, B. O. (2000a). The Escherichia coli MG1655 in silico metabolic genotype: Its definition, characteristics, and capabilities. Proceedings of the National Academy of Sciences USA, 97, 5528-5533.

Edwards, J. S., \& Palsson, B. O. (2000b). Robustness analysis of the Escherichia coli metabolic network. Biotechnology Progress, 16, 927-939.

Eissing, T., Allgöwer, F., \& Bullinger, E. (2005). Robustness properties of apoptosis models with respect to parameter variations and intrinsic noise. Systems Biology, IEE Proceedings, 152, 221-228.

Eissing, T., Conzelmann, H., Gilles, E. D., Allgöwer, F., Bullinger, E., \& Scheurich, P. (2004). Bistability analyses of a caspase activation model for receptor-induced apoptosis. Journal of Biological Chemistry, 279, 36892-36897.

Elmore, S. (2007). Apoptosis: A review of programmed cell death. Toxicologic Pathology, 35, 495-516.

Fagan, M. B. (2012). Waddington redux: Models and explanation in stem cell and systems biology. Biology and Philosophy, 27, 179-213.

Faratian, D., Clyde, R. G., Crawford, J. W., \& Harrison, D. J. (2009). Systems pathologytaking molecular pathology into a new dimension. Nature Review Clininical Oncolology, 6, 455-464.

Fell, D. A. (2007). How can we understand metabolism? In F. C. Boogerd, F. J. Bruggeman, J.H. S. Hofmeyr, \& H. V. Westerhoff (Eds.), Systems biology: Philosophical foundations (pp. 87-101). Amsterdam: Elsevier.

Ferrell, J. E., Tsai, T. Y.-C., \& Yang, Q. (2011). Modeling the cell cycle: Why do certain circuits oscillate? Cell, $144,874-885$.

Fisher, J., Piterman, N., Hajnal, A., \& Henzinger, T. A. (2007). Predictive modeling of signaling crosstalk during C. elegans vulval development. PLoS Computational Biology, 3, e92.

Fraser, I. D. C., \& Germain, R. N. (2009). Navigating the network: Signaling cross-talk in hematopoietic cells. Nature Immunology, 10, 327-331.

Fu, P., \& Panke, S. (Eds.). (2009). Systems biology and synthetic biology. Hoboken: Wiley.

Fussenegger, M., Bailey, J. E., \& Varner, J. (2000). A mathematical model of caspase function in apoptosis. Nature Biotechnology, 18, 768-774.

Gerson, E. M. (this issue). Integration of specialties: An institutional and organizational view. Studies in History and Philosophy of Biological and Biomedical Sciences. doi:10.1016/j.shpsc.2012.10.002

Glennan, S., Darden, L., \& Woodward, J. (2002). 'Mechanism: Explanation, discovery, and experimentation' (PSA 2000 symposium). Philosophy of Science, 69, S342-S377.

Goldbeter, A., \& Pourquié, O. (2008). Modeling the segmentation clock as a network of coupled 
oscillations in the Notch, Wnt and FGF signaling pathways. Journal of Theoretical Biology, 252, 574-585.

Green, S. (2013). When one model is not enough: Combining epistemic tools in systems biology. Studies in History and Philosophy of Biological and Biomedical Sciences, 44, 170-180.

Greenbury, S. F., Johnston, I. G., Smith, M. A., Doye, J. P. K., \& Louis, A. A. (2010). The effect of scale-free topology on the robustness and evolvability of genetic regulatory networks. Journal of Theoretical Biology, 267, 48-61.

Griesemer, J. (this issue). Integration of approaches in David Wake's model-taxon research platform for evolutionary morphology. Studies in History and Philosophy of Biological and Biomedical Sciences. doi:10.1016/j.shpsc.2013.03.021

Helms, V. (2008). Principles of computational cell biology. Weinheim: Wiley-VHC.

Hempel, C. G. (1965). Aspects of scientific explanation and other essays in the philosophy of science. New York: Free Press.

Hempel, C. G., \& Oppenheim, P. (1948). Studies in the logic of explanation. Philosophy of Science, $15,135-175$.

Hentschel, H. G. E., Glimm, T., Glazier, J. A., \& Newman, S. A. (2004). Dynamical mechanisms for skeletal pattern formation in the vertebrate limb. Proceedings of the Royal Society of London B: Biological Sciences, 271, 1713-1722.

Herrgen, L., Ares, S., Morelli, L. G., Schröter, C., Jülicher, F., \& Oates, A. C. (2010). Intercellular coupling regulates the period of the segmentation clock. Current Biology 20, 1244-1253.

Ho, K. L., \& Harrington, H. A. (2010). Bistability in apoptosis by receptor clustering. PLoS Comput Biol, 6, e1000956.

Hooker, C. (Ed.). (2011). Philosophy of complex systems. Amsterdam: Elsevier.

Ihekwaba, A. E. C., Broomhead, D. S., Grimley, R., Benson, N., White, M. R. H., \& Kell, D. B. (2005). Synergistic control of oscillations in the $\mathrm{nf}-\mathrm{\kappa b}$ signalling pathway. IEE Proceedings Systems Biology, 152, 153-160.

Ihmels, J., Collins, S. R., Schuldiner, M., Krogan, N. J., \& Weissman, J. S. (2007). Backup without redundancy: Genetic interactions reveal the cost of duplicate gene loss. Molecular Systems Biology, 3.

Ingolia, N. T. (2004). Topology and robustness in the Drosophila segment polarity network. PLoS Biology, 2, e123.

Jansson, J. K., Neufeld, J. D., Moran, M. A., \& Gilbert, J. A. (2012). Omics for understanding microbial functional dynamics. Environmental Microbiology, 14, 1-3.

Jeong, H., Tombor, B., Albert, R., Oltvai, Z. N., \& Barabási, A. L. (2000). The large-scale organization of metabolic networks. Nature, 407, 651-654.

Jørgensen, C., \& Linding, R. (2010). Simplistic pathways or complex networks? Current Opinion in Genetics \& Development, 20, 15-22. 
Kafri, R., Bar-Even, A., \& Pilpel, Y. (2005). Transcription control reprogramming in genetic backup circuits. Nature Genetics, 37, 295-299.

Kaplan, D. M., \& Craver, C. F. (2011). The explanatory force of dynamical and mathematical models in neuroscience: A mechanistic perspective. Philosophy of Science, 78, 601-627.

Karr, J. R., Sanghvi, J. C., Macklin, D. N., Gutschow, M. V., Jacobs, J. M., Bolival, B., AssadGarcia, N., Glass, J. I., \& Covert, M. W. (2012). A whole-cell computational model predicts phenotype from genotype. Cell, 150, 389-401.

Kirschner, M. W., \& Gerhart, J. C. (2005). The plausibility of life: Resolving Darwin's dilemma. New Haven: Yale University Press.

Kitano, H. (2004a). Biological robustness. Nature Reviews Genetics, 5, 826-837.

Kitano, H. (2004b). Cancer as a robust system: Implications for anticancer therapy. Nature Reviews Cancer, 4, 227-235.

Kitano, H. (2006). Computational cellular dynamics: A network-physics integral. Nature Reviews Molecular Cell Biology, 7, 163.

Kitano, H. (Ed.). (2001). Foundations of systems biology. Cambridge, MA: MIT Press.

Klipp, E., Liebermeister, W., Wierling, C., Kowald, A., Lehrach, H., \& Herwig, R. (2010). Systems biology: A textbook. Weinheim: Wiley-VCH.

Krohs, U., \& Callebaut, W. (2007). Data without models merging with models without data. In F. C. Boogerd, F. J. Bruggeman, J.-H. S. Hofmeyr, \& H. V. Westerhoff (Eds.), Systems biology: Philosophical foundations (pp. 181-213). Amsterdam: Elsevier.

Lavrik, I. N. (Ed.). (2013). Systems biology of apoptosis. Berlin: Springer.

Layek, R. K., Datta, A., \& Dougherty, E. R. (2011). From biological pathways to regulatory networks. Molecular BioSystems, 7, 843-851.

Legewie, S., Blüthgen, N., \& Herzel, H. (2006). Mathematical modeling identifies inhibitors of apoptosis as mediators of positive feedback and bistability. PLoS Computational Biology, 2 , e120.

Leonelli, S. (this issue). Integrating data to acquire new knowledge: Three modes of integration in plant science. Studies in History and Philosophy of Biological and Biomedical Sciences. doi:10.1016/j.shpsc.2013.03.020

Levy, A. (in press). What was Hodgkin and Huxley's achievement? British Journal for the Philosophy of Science. doi:10.1093/bjps/axs043

Levy, A., \& Bechtel, W. (2013). Abstraction and the organization of mechanisms. Philosophy of Science, 80, 241-261.

Li, R., \& Bowerman, B. (2010a). Symmetry breaking in biology. Cold Spring Harbor Perspectives in Biology, 2, a003475.

Li, R., \& Bowerman, B. (Eds.). (2010b). Symmetry breaking in biology. Cold Spring Harbor: Cold Spring Harbor Laboratory Press.

Li, X., Cassidy, J. J., Reinke, C. A., Fischboeck, S., \& Carthew, R. W. (2009). A microRNA 
imparts robustness against environmental fluctuation during development. Cell, 137, 273282.

Linksvayer, T. A., Fewell, J. H., Gadau, J., \& Laubichler, M. D. (2012). Developmental evolution in social insects: Regulatory networks from genes to societies. Journal of Experimental Zoology Part B: Molecular and Developmental Evolution, 318, 159-169.

Machamer, P., Darden, L., \& Craver, C. F. (2000). Thinking about mechanisms. Philosophy of Science, 67, 1-25.

Manu, Surkova, S., Spirov, A. V., Gursky, V. V., Janssens, H., Kim, A.-R., Radulescu, O., Vanario-Alonso, C. E., Sharp, D. H., Samsonova, M., \& Reinitz, J. (2009a). Canalization of gene expression and domain shifts in the Drosophila blastoderm by dynamical attractors. PLoS Computational Biology, 5, e1000303.

Manu, Surkova, S., Spirov, A. V., Gursky, V. V., Janssens, H., Kim, A.-R., Radulescu, O., Vanario-Alonso, C. E., Sharp, D. H., Samsonova, M., \& Reinitz, J. (2009b). Canalization of gene expression in the Drosophila blastoderm by gap gene cross regulation. PLoS Biology, 7, e1000049.

Masamizu, Y., Ohtsuka, T., Takashima, Y., Nagahara, H., Takenaka, Y., Yoshikawa, K., Okamura, H., \& Kageyama, R. (2006). Real-time imaging of the somite segmentation clock: Revelation of unstable oscillators in the individual presomitic mesoderm cells. Proceedings of the National Academy of Sciences USA, 103, 1313-1318.

Maull, N. (1977). Unifying science without reduction. Studies in the History and Philosophy of Science, 8, 143-171.

Mazzitello, K. I., Arizmendi, C. M., \& Hentschel, H. G. E. (2008). Converting genetic network oscillations into somite spatial patterns. Physical Review E, 78, 021906.

Meinhardt, H. (2009). The algorithmic beauty of sea shells, 4th edition. Berlin: Springer.

Milloz, J., Duveau, F., Nuez, I., \& Félix, M.-A. (2008). Intraspecific evolution of the intercellular signaling network underlying a robust developmental system. Genes \& Development, 22, 3064-3075.

Mitchell, S. D. (2009). Unsimple truths: Science, complexity, and policy. Chicago: University of Chicago Press.

Mitchell, S. D. (2012). Emergence: Logical, functional and dynamical. Synthese, 185, 171-186.

Mogilner, A., Allard, J., \& Wollman, R. (2012). Cell polarity: Quantitative modeling as a tool in cell biology. Science, 336, 175-179.

Morelli, L. G., Ares, S., Herrgen, L., Schröter, C., Jülicher, F., \& Oates, A. C. (2009). Delayed coupling theory of vertebrate segmentation. HFSP Journal, 3, 55-66.

Morelli, L. G., Uriu, K., Ares, S., \& Oates, A. C. (2012). Computational approaches to developmental patterning. Science, 336, 187-191.

Moreno, A. (2007). A systemic approach to the origin of biological organization. In F. C. Boogerd, F. J. Bruggeman, J.-H. S. Hofmeyr, \& H. V. Westerhoff (Eds.), Systems biology: 
Philosophical foundations (pp. 243-268). Amsterdam: Elsevier.

Murray, J. D. (2003). Mathematical biology II: Spatial models and biomedical applications. Berlin: Springer.

Nakamasu, A., Takahashi, G., Kanbe, A., \& Kondo, S. (2009). Interactions between zebrafish pigment cells responsible for the generation of Turing patterns. Proceedings of the National Academy of Sciences USA, 106, 8429-8434.

Newman, S. A., \& Bhat, R. (2007). Activator-inhibitor dynamics of vertebrate limb pattern formation. Birth Defects Research Part C: Embryo Today: Reviews, 81, 305-319.

Newman, S. A., Christley, S., Glimm, T., Hentschel, H. G. E., Kazmierczak, B., Zhang, Y.-T., Zhu, J., \& Alber, M. S. (2008). Multiscale models for vertebrate limb development. In S. Schnell, P. K. Maini, S. A. Newman, \& T. J. Newman (Eds.), Multiscale modeling of developmental systems (pp. 311-340). New York: Academic Press.

Newman, S. A., \& Müller, G. B. (2005). Origination and innovation in the vertebrate limb skeleton: An epigenetic perspective. Journal of Experimental Zoology Part B: Molecular and Developmental Evolution, 304B, 593-609.

Noble, D. (2002). Modeling the heart—from genes to cells to the whole organ. Science, 295 , 1678-1682.

Noble, D. (2006). The music of life: Biology beyond the genome. Oxford: Oxford University Press.

O'Malley, M. A. (this issue). When integration fails: Prokaryote phylogeny and the tree of life. Studies in History and Philosophy of Biological and Biomedical Sciences.

O'Malley, M. A., \& Dupré, J. (2005). Fundamental issues in systems biology. BioEssays, 27, 1270-1276.

O'Malley, M. A., \& Soyer, O. S. (2012). The roles of integration in molecular systems biology. Studies in History and Philosophy of Biological and Biomedical Sciences, 43, 58-68.

Oates, A. C., Morelli, L. G., \& Ares, S. (2012). Patterning embryos with oscillations: Structure, function and dynamics of the vertebrate segmentation clock. Development, 139, 625-639.

Patel, M., \& Nagl, S. (Eds.). (2010). The role of model integration in complex systems modelling: An example from cancer biology. Berlin: Springer.

Plikus, M. V., Baker, R. E., Chen, C.-C., Fare, C., de la Cruz, D., Andl, T., Maini, P. K., Millar, S. E., Widelitz, R., \& Chuong, C.-M. (2011). Self-organizing and stochastic behaviors during the regeneration of hair stem cells. Science, 332, 586-589.

Plutynski, A. (this issue). Cancer and the goals of integration. Studies in History and Philosophy of Biological and Biomedical Sciences. doi:10.1016/j.shpsc.2013.03.019

Putnam, H. (1975). Philosophy and our mental life. In H. Putnam (Ed.), Mind, language and reality (Philosophical papers, vol. 2) (pp. 291-303). Cambridge: Cambridge University Press.

Riedel-Kruse, I. H., Müller, C., \& Oates, A. C. (2007). Synchrony dynamics during initiation, 
failure, and rescue of the segmentation clock. Science, 317, 1911-1915.

Robins, S. K., \& Craver, C. F. (2009). Biological clocks: Explaining with models of mechanisms. In J. Bickle (Ed.), Oxford handbook of philosophy and neuroscience (pp. 4167). Oxford: Oxford University Press.

Salazar-Ciudad, I., \& Jernvall, J. (2002). A gene network model accounting for development and evolution of mammalian teeth. Proceedings of the National Academy of Sciences USA, 99, 8116-8120.

Salazar-Ciudad, I., \& Jernvall, J. (2010). A computational model of teeth and the developmental origins of morphological variation. Nature, 464, 583-586.

Santillán, M., \& Mackey, M. C. (2008). A proposed mechanism for the interaction of the segmentation clock and the determination front in somitogenesis. PLOS ONE, 3, e1561.

Schnell, S., Maini, P. K., Newman, S. A., \& Newman, T. J. (Eds.). (2008). Multiscale modeling of developmental systems. New York: Academic Press.

Shiraishi, T., Matsuyama, S., \& Kitano, H. (2010). Large-scale analysis of network bistability for human cancers. PLoS Computational Biolology, 6, e1000851.

Siegal, M., Promislow, D., \& Bergman, A. (2007). Functional and evolutionary inference in gene networks: Does topology matter? Genetica, 129, 83-103.

Smart, A. G., Amaral, L. A. N., \& Ottino, J. M. (2008). Cascading failure and robustness in metabolic networks. Proceedings of the National Academy of Sciences USA, 105, 1322313228.

Soriano, J., Rüdiger, S., Pullarkat, P., \& Ott, A. (2009). Mechanogenetic coupling of Hydra symmetry breaking and driven Turing instability model. Biophysical Journal, 96, 16491660 .

Strevens, M. (2008). Depth: An account of scientific explanation. Harvard: Harvard University Press.

Turing, A. M. (1952). The chemical basis of morphogenesis. Philosophical Transactions of the Royal Society of London B: Biological Sciences, 237, 37-72.

Umulis, D., O'Connor, M. B., \& Othmer, H. G. (2008). Robustness of embryonic spatial patterning in Drosophila melanogaster. In S. Schnell, P. K. Maini, S. A. Newman, \& T. J. Newman (Eds.), Multiscale modeling of developmental systems (pp. 65-111). New York: Academic Press.

Uriu, K., Morishita, Y., \& Iwasa, Y. (2010). Random cell movement promotes synchronization of the segmentation clock. Proceedings of the National Academy of Sciences USA, 107, 4979-4984.

van der Gucht, J., \& Sykes, C. (2009). Physical model of cellular symmetry breaking. Cold Spring Harbor Perspectives in Biology, 1, a001909.

von Dassow, G., Meir, E., Munro, E. M., \& Odell, G. M. (2000). The segment polarity network is a robust developmental module. Nature, 406, 188-192. 
von Dassow, G., \& Odell, G. M. (2002). Design and constraints of the Drosophila segment polarity module: Robust spatial patterning emerges from intertwined cell state switches. Journal of Experimental Zoology (Molecular and Developmental Evolution), 294, 179-215.

Wagner, A. (2005a). Distributed robustness versus redundancy as causes of mutational robustness. BioEssays, 27, 176-188.

Wagner, A. (2005b). Robustness and evolvability in living systems. Princeton: Princeton University Press.

Wang, E. (Ed.). (2010). Cancer systems biology. Boca Raton: CRC Press.

Wang, Y., Zhang, X.-S., \& Xia, Y. (2009). Predicting eukaryotic transcriptional cooperativity by Bayesian network integration of genome-wide data. Nucleic Acids Research, 37, 5943-5958.

Weiss, J. N., Qu, Z., \& Garfinkel, A. (2003). Understanding biological complexity: Lessons from the past. FASEB Journal, 17, 1-6.

Westerhoff, H. V., \& Kell, D. B. (2007). The methodologies of systems biology. In F. C. Boogerd, F. J. Bruggeman, J.-H. S. Hofmeyr, \& H. V. Westerhoff (Eds.), Systems biology: Philosophical foundations (pp. 23-70). Amsterdam: Elsevier.

Wilhelm, T. (2009). The smallest chemical reaction system with bistability. BMC Systems Biology, 3, 90.

Wimsatt, W. C. (2007). Re-engineering philosophy for limited beings: Piecewise approximations to reality. Cambridge, MA: Harvard University Press.

Wing, S. S., Lecker, S. H., \& Jagoe, R. T. (2011). Proteolysis in illness-associated skeletal muscle atrophy: From pathways to networks. Critical Reviews in Clinical Laboratory Science, 48, 49-70. 2011/06/28

Winther, R. G. (2006). Parts and theories in compositional biology. Biology and Philosophy, 21, 471-499.

Wolkenhauer, O., \& Muir, A. (2011). The complexity of cell-biological systems. In C. Hooker (Ed.), Philosophy of complex systems (pp. 355-385). Amsterdam: Elsevier.

Woodward, J. (2002). What is a mechanism? A counterfactual account. Philosophy of Science, 69, S366-S377.

Woodward, J. (2003). Making things happen: A theory of causal explanation. Oxford: Oxford University Press.

Yang, Q., \& Ferrell, J. E. (2013). The Cdk1-APC/C cell cycle oscillator circuit functions as a time-delayed, ultrasensitive switch. Nature Cell Biology, 15, 519-525.

Zhu, J., Zhang, Y.-T., Alber, M. S., \& Newman, S. A. (2010). Bare bones pattern formation: A core regulatory network in varying geometries reproduces major features of vertebrate limb development and evolution. PLOS ONE, 5, e10892. 


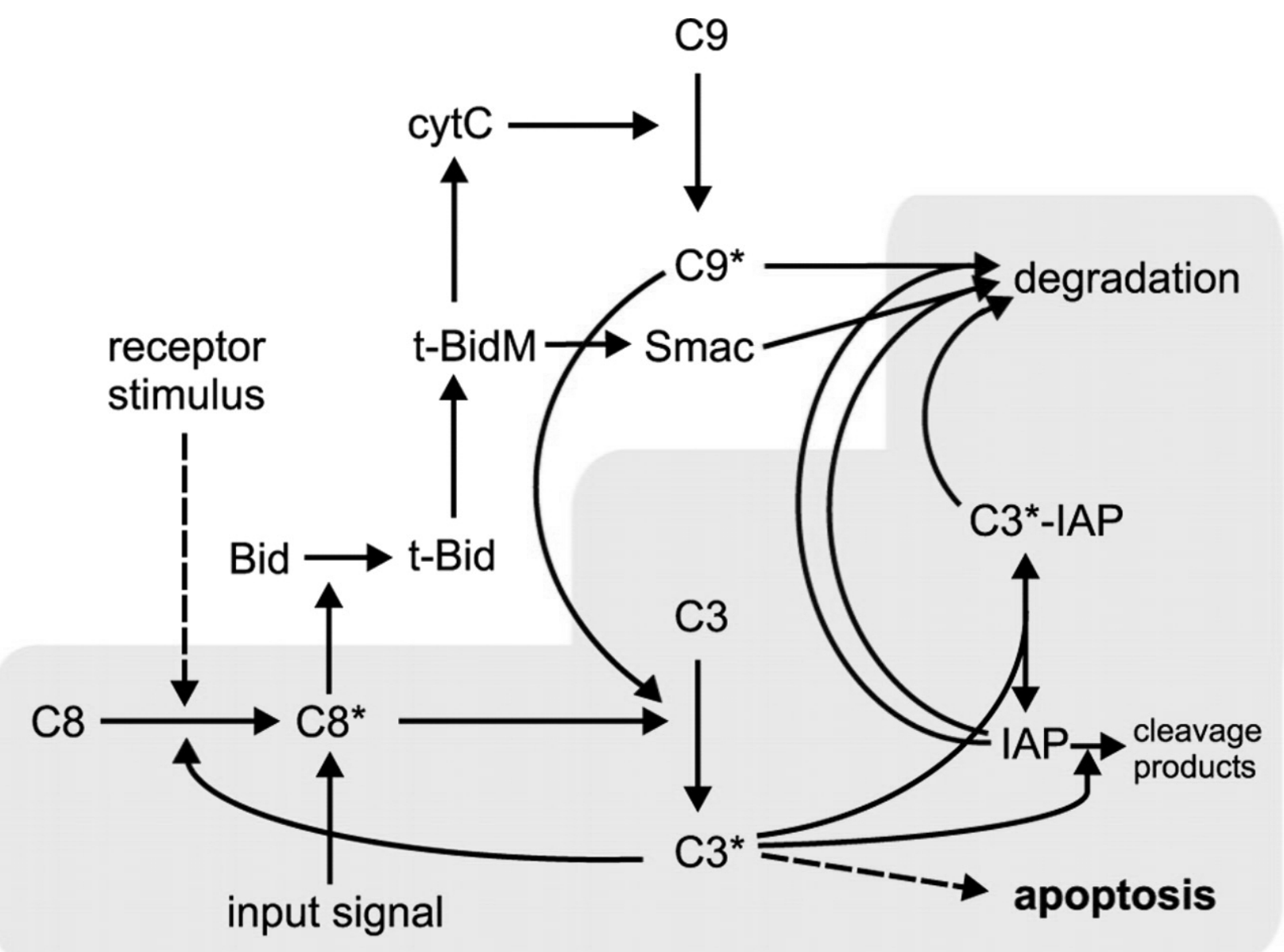

Fig. 1. Pathways on which Eissing et al. based their models of apoptosis (grey area is the extrinsic, death receptor initiated pathway mathematically modeled; from Eissing et al., 2004). 


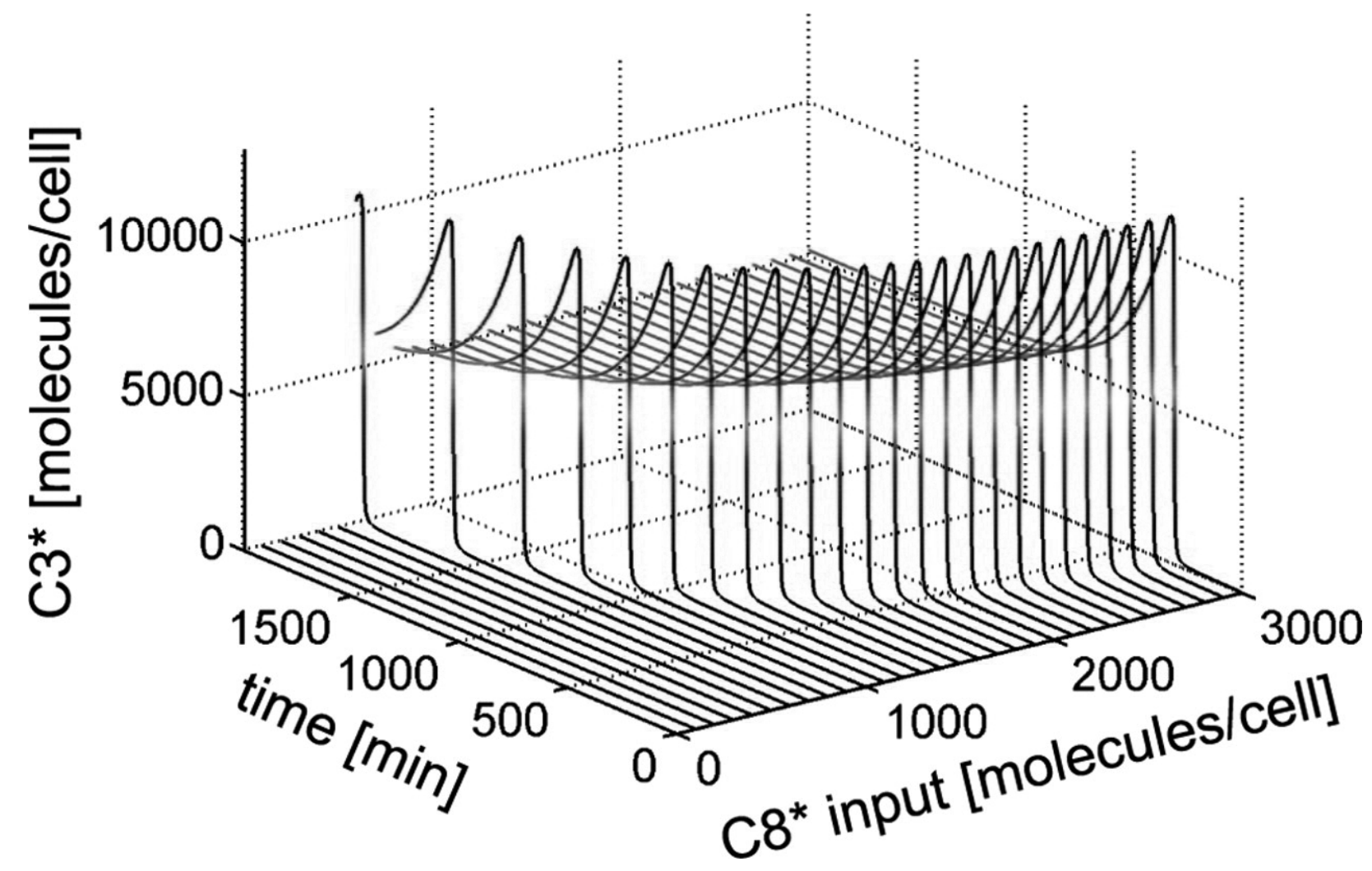

Fig. 2. Bistable behavior in the extended apoptosis model (from Eissing et al., 2004). 


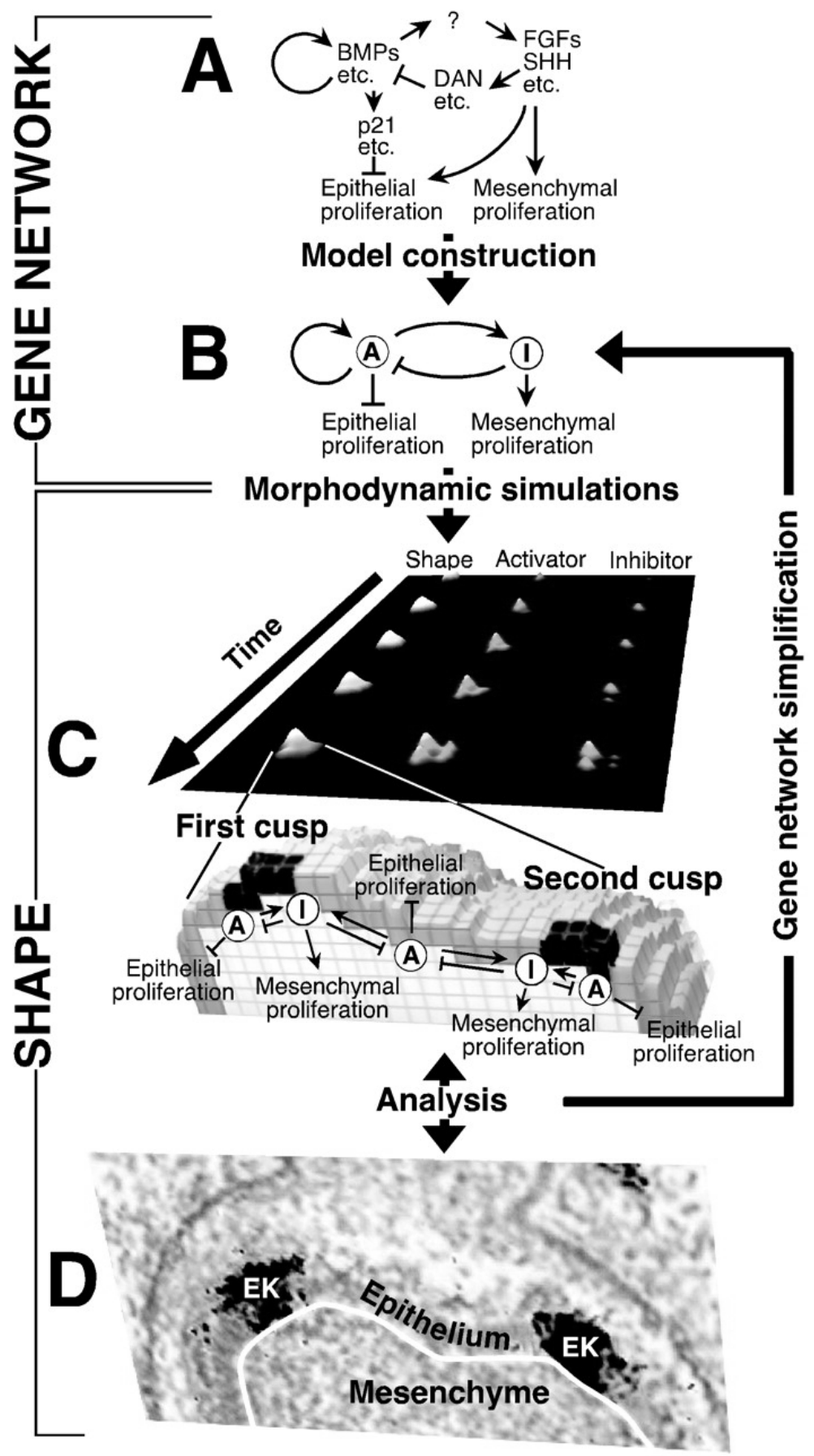

Fig. 3. Modeling the development of mammalian teeth. An experimentally obtained molecular network (A) forms the basis of a simplified activator-inhibitor system (B). The mathematical model's prediction of the three-dimensional tooth shape and the activator and inhibitor distributions across developmental time $(\mathrm{C})$ is compared to empirical information in mice (D); EK = enamel knot (from Salazar-Ciudad \& Jernvall, 2002). 

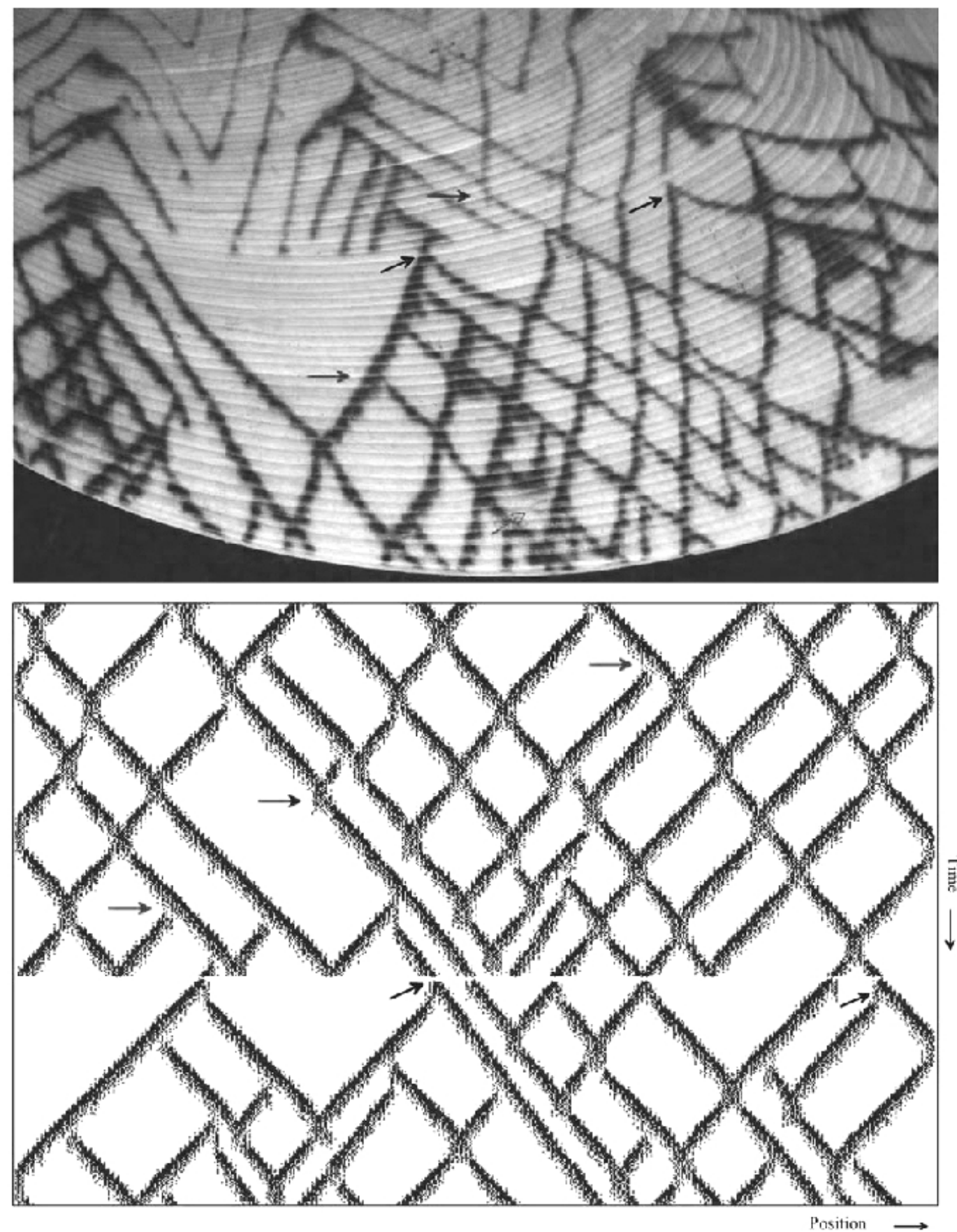

Fig. 4. Sea shell coloration pattern in Tapes literatus (upper half), and Meinhardt's simulation using an activator-inhibitor model, where the arrows denote motifs also present in the real shell (from Meinhardt, 2009). 


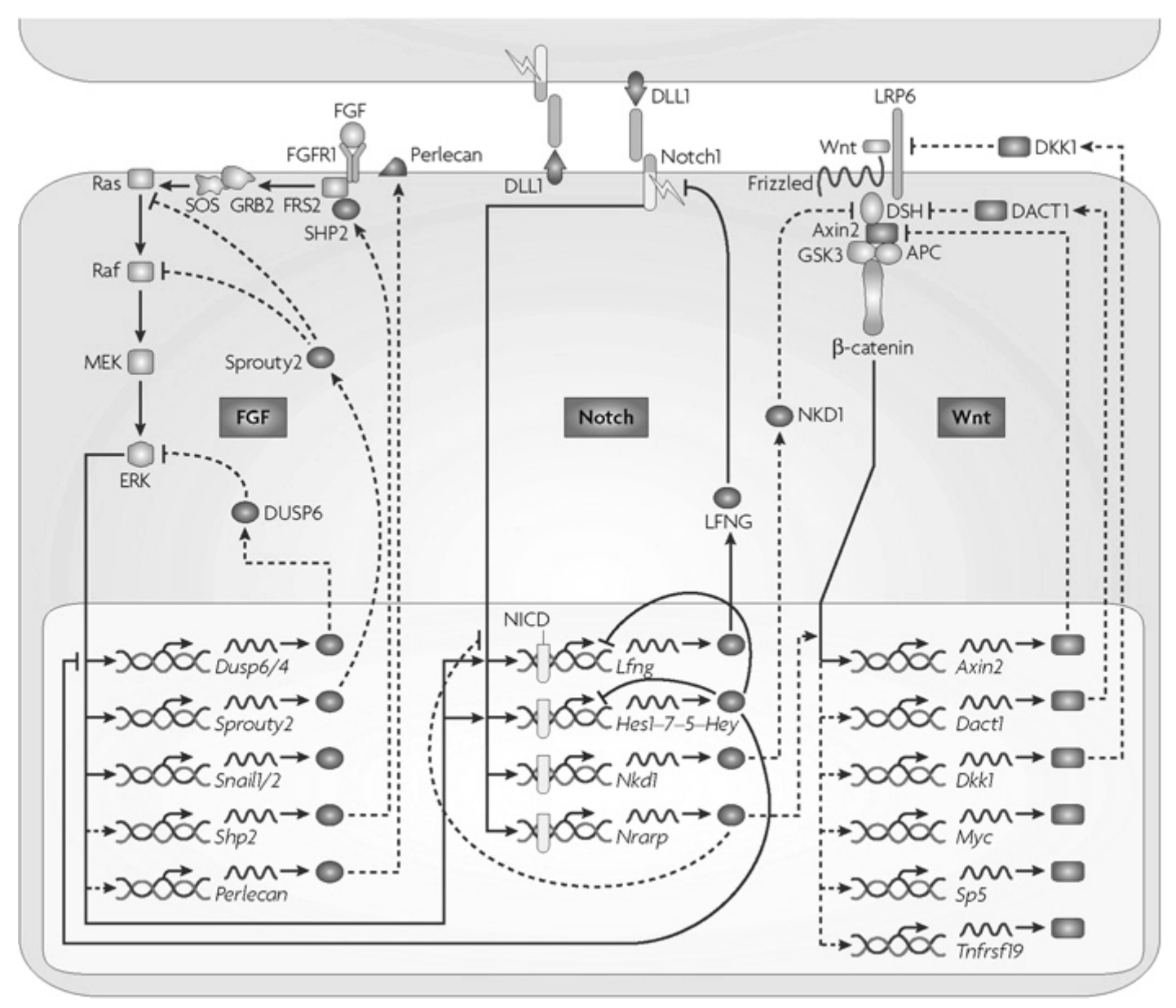

Fig. 5. The segmentation clock in mice. Apart from components involved in the synchronization with another cell (top), the figure shows three major signaling pathways (FGF, Notch, and Wnt) underlying the generation of oscillations (from Dequéant \& Pourquié, 2008; the area with light background in lower half is the cell nucleus containing oscillatory genes and their mRNA transcripts; dashed lines are interactions inferred from other species or microarray data). 